\title{
Senescent skeletal cells cross-talk with synovial cells plays a key role in the pathogenesis of osteoarthritis
}

\author{
Chong-Jie Wu ${ }^{1 \dagger}$, Ri-Xu Liu ${ }^{1 \dagger}$, Song-Wei Huan ${ }^{1,2 \dagger}$, Wang Tang ${ }^{1}$, Yu-Kai Zeng ${ }^{1}$, Jun-Cheng Zhang ${ }^{1}$, Jie Yang ${ }^{1,2}$, \\ Zhen-Yan Li ${ }^{1,2}$, Ying Zhou' ${ }^{1}$ Zhen-Gang Zha ${ }^{1,2}$, Huan-Tian Zhang ${ }^{1,2^{*}}$ and Ning Liu ${ }^{1,2^{*}}$
}

\begin{abstract}
Osteoarthritis $(\mathrm{OA})$ has been recognized as an age-related degenerative disease commonly seen in the elderly that affects the whole "organ" including cartilage, subchondral bone, synovium, and muscles. An increasing number of studies have suggested that the accumulation of senescent cells triggering by various stresses in the local joint contributes to the pathogenesis of age-related diseases including OA. In this review, we mainly focus on the role of the senescent skeletal cells (chondrocytes, osteoblasts, osteoclasts, osteocyte, and muscle cells) in initiating the development and progression of OA alone or through cross-talk with the macrophages/synovial cells. Accordingly, we summarize the current OA-targeted therapies based on the abovementioned theory, e.g., by eliminating senescent skeletal cells and/or inhibiting the senescence-associated secretory phenotype (SASP) that drives senescence. Furthermore, the existing animal models for the study of OA from the perspective of senescence are highlighted to fill the gap between basic research and clinical applications. Overall, in this review, we systematically assess the current understanding of cellular senescence in OA, which in turn might shed light on the stratified OA treatments.
\end{abstract}

Keywords: Osteoarthritis, Skeletal cells, Cellular senescence, SASP, Targeted therapies, Animal models

\section{Introduction}

Osteoarthritis (OA) is the most common age-related disease that affects the elderly [1]. Currently, it is estimated to be the fourth leading cause of pain and physical disability (deformity and limited range of motion) [2]. A great number of patients with late-stage OA have to undergo surgical interventions [3, 4]; thus, OA has a significant impact on the individuals, health-care systems, and society $[5,6]$. A better understanding of the precise mechanisms that drive OA progression will shed light on the stratified treatment of OA.

\footnotetext{
*Correspondence: zhanghuantian@jnu.edu.cn; liuning@jnu.edu.cn ${ }^{\dagger}$ Chong-Jie Wu, Ri-Xu Liu and Song-Wei Huan contributed equally to this work.

${ }^{1}$ Department of Bone and Joint Surgery, the First Affiliated Hospital, Jinan University, Guangzhou 510630, Guangdong, China

Full list of author information is available at the end of the article
}

Cellular senescence is an important process induced by various types of stresses that leads to irreversible proliferative cell cycle arrest and distinctive cellular phenotypic alteration [6-9]. Recently, several studies have highlighted the crucial role of senescent skeletal cells in the development and progression of OA [10,11]. Additionally, the cross-talk of synovial cells in a joint with various senescent musculoskeletal cells may facilitate the pathogenesis of OA by amplifying the overlapping inflammatory response and/or by triggering the senescence-associated secretory phenotype (SASP) [12]. Accordingly, therapies aiming to eliminate the senescent cells are investigated in a series of OA models [13]. These findings have deepened our understanding of mechanisms of OA from the perspective of cellular senescence and thereby suggesting novel strategies for stratified OA therapy. original author(s) and the source, provide a link to the Creative Commons licence, and indicate if changes were made. The images or other third party material in this article are included in the article's Creative Commons licence, unless indicated otherwise in a credit line to the material. If material is not included in the article's Creative Commons licence and your intended use is not permitted by statutory regulation or exceeds the permitted use, you will need to obtain permission directly from the copyright holder. To view a copy of this licence, visit http://creativecommons.org/licenses/by/4.0/. The Creative Commons Public Domain Dedication waiver (http://creativeco mmons.org/publicdomain/zero/1.0/) applies to the data made available in this article, unless otherwise stated in a credit line to the data. 


\section{Key stimuli for cellular senescence and OA}

Cellular senescence was first described by Hayflick and Moorhead in 1961, in which two main types of cellular senescence, e.g., replicative senescence and premature senescence, were included [14]. Replicative senescence refers to a state of reduced replicative capacity causing by telomere shortening, while premature senescence which defined as cell cycle arrest is induced by oxidative stress and DNA damage [15]. Typical features of this type of cellular senescence included increasing the expression of $\mathrm{p} 21, \mathrm{p} 16$, and $\mathrm{p} 53$, and elevated the senescenceassociated- $\beta$-galactosidase (SA- $\beta$-Gal) activity and high levels of reactive oxygen species (ROS) [16]. The liberation of p16 suppression caused early cell senescence [17], while p53, p21 (CIP1) and p15 (INK4b) increased in pre-senescent cells [18]. On the other hand, the increase of $\mathrm{Bcl}-\mathrm{XL}$ in pre-senescence cells enhanced their own anti-apoptotic ability, which made the cells progress to senescence rather than apoptosis [19]. In addition, the metabolic activities and secretion levels of the SASP and the proinflammatory cytokine in the senescent cells were demonstrated to be altered [20]. In a recent study, it was found that the combination of mitogenic stimulation and DNA damage induced chondrocyte senescence and increase the production of senescence marker: SA- $\beta-G a l$, p16, and $\gamma \mathrm{H} 2 \mathrm{AX}$, etc. [21].

\section{Telomeres}

Telomeres are nucleoprotein structures at the ends of linear chromosomes that ensure genome stability by protecting DNA extremities from fusion and degradation [22]. In the process of cell replication, telomeres gradually shorten and lose the function of protecting DNA stability. As a result, DNA repair machinery is initiated during the DNA damage response which leads to aging [23]. Chondrocytes in osteoarthritic cartilage may undergo a replicative senescence with associated phenotypic changes leading to the development of OA. Through a comparison of clinical specimens in a group of 15 patients with hip OA, 30 with knee OA, and 11 controls without joint disease, it has been found that the telomeres of OA patients were shorter than unaffected chondrocytes of controls [24]. In addition, the function of telomeres in protecting DNA is also related to telomerase. Cells lacking telomerase triggers the DNA damage response, which induces early onset of senescence thereby promoting the progression of osteoarthritis $[25,26]$.

In addition, oxidative stress and inflammation have been considered as important factors that accelerate the aging process by shortening telomeres and/ or causing telomere abrasion [27, 28]. This conclusion has been supported by a recent study showing that the relative telomere length (RTL) of leukocytes in knee OA is shorter than in age-matched healthy controls and that a negative correlation between oxidative stress, inflammatory factor levels, and leukocyte RTL is found in the knee joints of OA patients [29]. It is obvious from these previous findings that telomere length (TL) interventions can significantly slow the aging process, which highlighted an avenue for treating age-related diseases such as OA.

\section{Oxidative stress}

Oxidative stress is widely accepted as a major inducer of DNA damage and cellular senescence [30]. Mechanistically, it is demonstrated to induce cell senescence by upregulating the expression of p53 and p21, as well as activating the p38 mitogen-activated protein kinase (MAPK) and phosphatidylinositol 3 kinase (PI3K)/protein kinase $B(P K B)$ signaling pathways [31-33]. Previous studies have shown that the progression of OA is significantly associated with oxidative stress and ROS levels $[34,35]$. Oxidative stress is regulated by MAPK pathway members such as Jun N-terminal kinases (JNKs) and p38 [31]. It has been reported that the deletion of JNK1 and JNK2 in mice leads to more obvious cellular senescence in the cartilage and synovium than is observed in wildtype mice, thereby exhibiting a more severe OA phenotype [36]. This suggests that JNK plays an important role in the progression of age-induced OA. In addition, studies have found that intracellular ROS levels, especially superoxide anion levels, are elevated in posttraumatic OA mouse model [20]. The accumulation of superoxide anions is associated with a downregulation of its degrading enzyme, mitochondrial superoxide dismutase 2 (SOD2) [37]. This association has also been demonstrated in patients with OA. The expression of SOD is downregulated and the production of intracellular superoxide is increased [38].

On the other hand, overproduction of ROS might also increase oxidative stress, and the latter plays a crucial role in the destruction of homeostasis in articular cartilage by suppressing autophagy, which together aggravates the severity of OA $[39,40]$. Consistently, oxidative stress, which is related to an increase in ROS and a decrease in antioxidant levels, is considered to be an important factor in the occurrence and development of OA. This evidence was obtained from a recent study demonstrating that the ROS scavenger vitamin $C$ prevents chondrocyte senescence in PTOA rat models [41], indicating that modulation of oxidative stress might be beneficial for cartilage by reducing ROS. Therefore, the imbalance between ROS production and the antioxidant capacities of cells is now considered a potential factor in the development of $\mathrm{OA}$ (Table 1). 
Table 1 Telomeres and oxidative stress contribute to cellular senescence also related to OA

\begin{tabular}{|c|c|c|c|c|}
\hline Factors & Correlation with senescence & Refs & Correlation with $\mathrm{OA}$ & Refs \\
\hline \multirow[t]{4}{*}{ Telomeres } & $\begin{array}{l}\text { DNA repair mechanisms recognized telomere shortening } \\
\text { triggers the DNA damage response leading to senescence }\end{array}$ & {$[23]$} & $\begin{array}{l}\text { Negative associations of oxidative stress and inflam- } \\
\text { matory factors levels with RTL in the knee joints of OA } \\
\text { patients }\end{array}$ & [29] \\
\hline & $\begin{array}{l}\text { Cells lacking telomerase trigger the DNA damage } \\
\text { response leading to senescence }\end{array}$ & [25] & Shorter TL in OA patients & [24] \\
\hline & $\begin{array}{l}\text { Oxidative stress accelerates cellular senescence by short- } \\
\text { ening telomeres }\end{array}$ & {$[27]$} & & \\
\hline & $\begin{array}{l}\text { Inflammation can lead to telomere abrasion inducing } \\
\text { cellular senescence }\end{array}$ & [28] & & \\
\hline \multirow[t]{3}{*}{ Oxidative stress } & $\begin{array}{l}\text { ROS accumulation, cell cycle arrest and cellular senes- } \\
\text { cence accompanied by upregulation of p53 and p21 } \\
\text { proteins in cells }\end{array}$ & {$[31]$} & $\begin{array}{l}\text { Increased levels of intracellular ROS disrupt cartilage } \\
\text { homeostasis and lead to cartilage damage in OA }\end{array}$ & [39] \\
\hline & Cellular senescence is largely dependent on ROS & {$[34,35]$} & Intracellular ROS level were elevated in posttraumatic OA & {$[20]$} \\
\hline & $\begin{array}{l}\text { ROS induced premature senescence by } \mathrm{PI} 3 \mathrm{~K} / \mathrm{Akt} / \mathrm{mTOR} \\
\text { pathway }\end{array}$ & [33] & $\begin{array}{l}\text { The production of intracellular superoxide is increased in } \\
\text { OA patients }\end{array}$ & [38] \\
\hline
\end{tabular}

$O A$ osteoarthritis, $R O S$ reactive oxygen species, $T L$ telomere length, $R T L$ relative telomere length

\section{Key signaling pathways for senescent cells and OA Signaling pathways associated with senescence}

The essential role of p53, p16, and p21 in cellular senescence has been extensively investigated; basically, they can be categorized into two major signaling pathways: the $\mathrm{p} 53 / \mathrm{p} 21$ and the $\mathrm{Rb} / \mathrm{p} 16$. Previous studies have revealed a higher expression of p16 in the articular chondrocytes of elderly mice and humans [42]. Remarkably, the selective elimination of p16 in p16 overexpressing cells can prolong the life span of mice [43].

Many stress stimuli can activate different signaling pathways and eventually cause cell cycle arrest via the p53/p21 and/or the Rb/p16 pathways. Although these two pathways share several common regulatory factors, p16/pRB pathway-induced cell growth arrest has been considered irreversible, while p53/p21 pathway-induced cell growth arrest is reversible [44]. A recent study has confirmed that activation of the Wnt/ $\beta$-catenin signaling pathway plays a role in the development of OA by downregulating the sirtuin 1(SIRT1) expression, while upregulating the expression of acetylated p53 and thus promoting the senescence of chondrocytes [32]. Omentin-1 is a newly discovered anti-inflammatory adipokine, and the expression of omentin-1 has been shown to reduce the expression of $\mathrm{p} 21$ and $\mathrm{p} 53$ acetylation by suppressing the SIRT1 reduction [45]. This study offers a possible treatment option for OA by the utilization of omentin-1.

\section{Signaling pathways relevant to the maintenance of senescent cells}

Senescent cells not only exhibit the characteristics of growth stagnation, but also favor the SASP, through which several extracellular proteases, inflammatory cytokines, growth factors, and chemokines such as granulocyte macrophage-colony stimulating factor (GM-CSF), growth-regulated oncogene (GRO) $\alpha, \beta, \gamma$, insulin-like growth factor-binding protein (IGFBP)-3, IGFBP-4, IGFBP-7, interleukin (IL)-1 $\alpha$, IL-6, IL-7, and IL- 8 are secreted $[46,47]$. The components of the SASP are highly cell-type-dependent and vary according to the inducer of senescence, the duration of senescence, and the surrounding microenvironment [48]. Studies have demonstrated that there is an overlap of the SASP and the secreted proinflammatory factors in skeletal cells [49-51]. The SASP molecules can exacerbate and spread pro-senescence effects by acting on senescent cells as well as neighboring cells through either autocrine and/ or paracrine manner. Factors such as IL- 6 and IL-8 might reinforce the senescent state in an autocrine manner in senescent cells, while many other SASP factors cause senescence in neighboring cells through paracrine action [52, 53] (Fig. 1).

Anti-apoptosis is necessary for senescent cells to protect themselves from proapoptotic SASP molecules. To achieve this protection, senescent cells activate several anti-apoptotic pathways (SCAPs) [54], including B cell lymphoma family inhibitors (Bcl-2, Bcl-XL, Bcl-W), PI3K/Akt pathways, p53/p21Cip1/serpine pathways, HIF- $1 \alpha$, and HSP-90 [55, 56]. Therefore, senescent cells can accumulate through these anti-apoptotic pathways.

In addition, senescent cells are recognized and removed by the immune system to slow the progression of agerelated diseases [57]. However, as aging progresses, the function of immune surveillance is largely diminished. As a result, senescent cells are not effectively phagocytosed or cleared timely [58], leading to the accumulation 


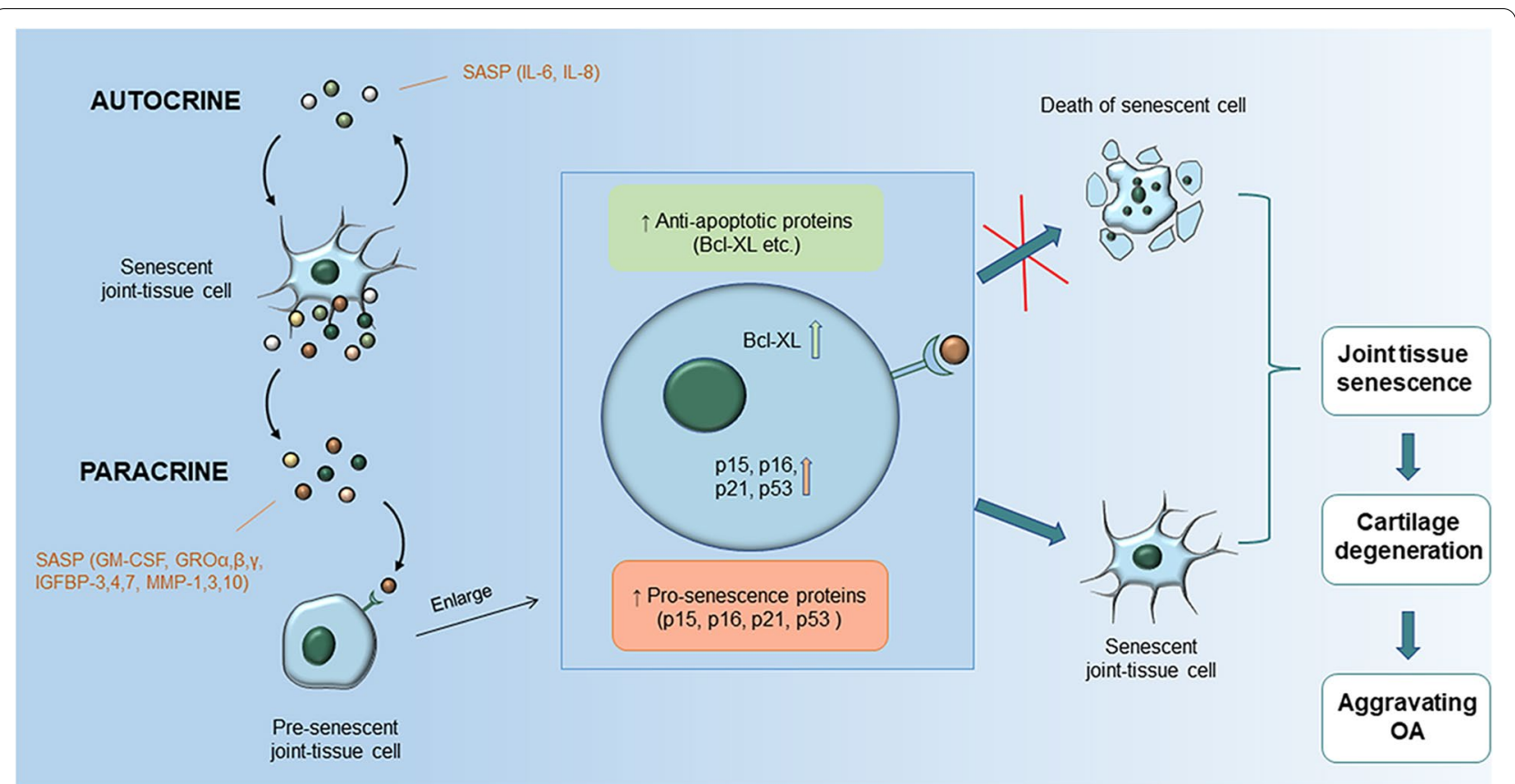

Fig. 1 SASP secreted by senescent cells accelerates senescence of surrounding cells. Cytokines such as IL-6 and IL-8 in SASP can act on senescent cells themselves in the form of autocrine, while many other SASP molecules are transmitted from cell to cell in a paracrine form to cause senescence in the neighboring cells, thus exacerbating the pro-senescence effect. p53, p21, p15, and p16 are increased in the pre-senescent cells. On the other hand, the increase of BCI-XL in the pre-senescence cells enhances their anti-apoptotic ability, which renders the cells undergo senescence instead of apoptosis. Senescent cells within the joint accelerate the progression of OA. IL, Interleukin; SASP, senescence-associated secretory phenotype; GM-CSF, granulocyte macrophage-colony stimulating factor; GRO, growth-regulated oncogene; IGFBP, insulin-like growth factor-binding protein; MMP, matrix metalloproteinase; $\mathrm{OA}$, osteoarthritis

of senescent cells in the local joint which accelerates the progression of age-related diseases such as OA.

\section{Autophagy-related signaling pathways}

Autophagy is essential for maintaining the integrity and function of articular cartilage. However, the deficiency of autophagy results in cellular senescence [59-61]. In 2015, two consecutive reports appeared in Science, proposing that GATA4 is a key protein in the relationship between cell senescence and autophagy $[62,63]$. More recently, it was found that METL3-mediated m6ATG7 modification regulates the autophagy-GATA4 axis to promote cell senescence and OA progression [64]. mTOR is a key regulator of autophagy and it is activated downstream of PI3 kinase and Akt kinase to inhibit autophagy. Studies have shown that mTOR is overexpressed in chondrocytes of OA patients and mouse models $[65,66]$. Additionally, the PI3K/Akt/mTOR axis has been reported to regulate chondrocyte death in an OA rat model $[67,68]$. Therefore, interfering the molecules in this signaling pathway may delay the progression of OA. Accumulating evidence also demonstrates that increased autophagy postpones cellular senescence by inhibiting the PI3K/Akt/mTOR signaling pathway. Beclin-1 promotes the formation of autophagosomes to induce autophagy. A study found that the expression of Beclin-1 inhibits the PI3K/Akt/mTOR signaling pathway thereby slowing the aging process of chondrocytes [69]. Furthermore, pituitary homeobox 1 (Pitx1) has been reported to be associated with cartilage degeneration [70]. Recently, a study confirmed that overexpression of Pitx1 increases the expression of SIRT1 and Beclin-1, inhibits the PI3K/Akt/mTOR signaling pathway, and increases autophagy levels thus preventing cellular senescence [71]. In contrast, targeted deletion of autophagy factor autophagy-related genes5 (ATG5), which is involved in the formation of complexes during autophagy, has been shown to promote age-related $\mathrm{OA}$ in mice and an increase in chondrocyte death was observed [72]. In view of the importance of autophagy in the pathogenesis of OA, studies have found that rapamycin, an mTOR inhibitor, activates autophagy to reduce the severity of osteoarthritis $[73,74]$.

Mitochondria are the "engines" of the cell, providing the cell with "fuel," which is ATP, and participating in the energy metabolism of the cell [75]. Thus, mitochondrial homeostasis plays an important role in maintaining cellular function. Mitophagy is a key mechanism for maintaining mitochondrial homeostasis [76]. PTEN-induced 


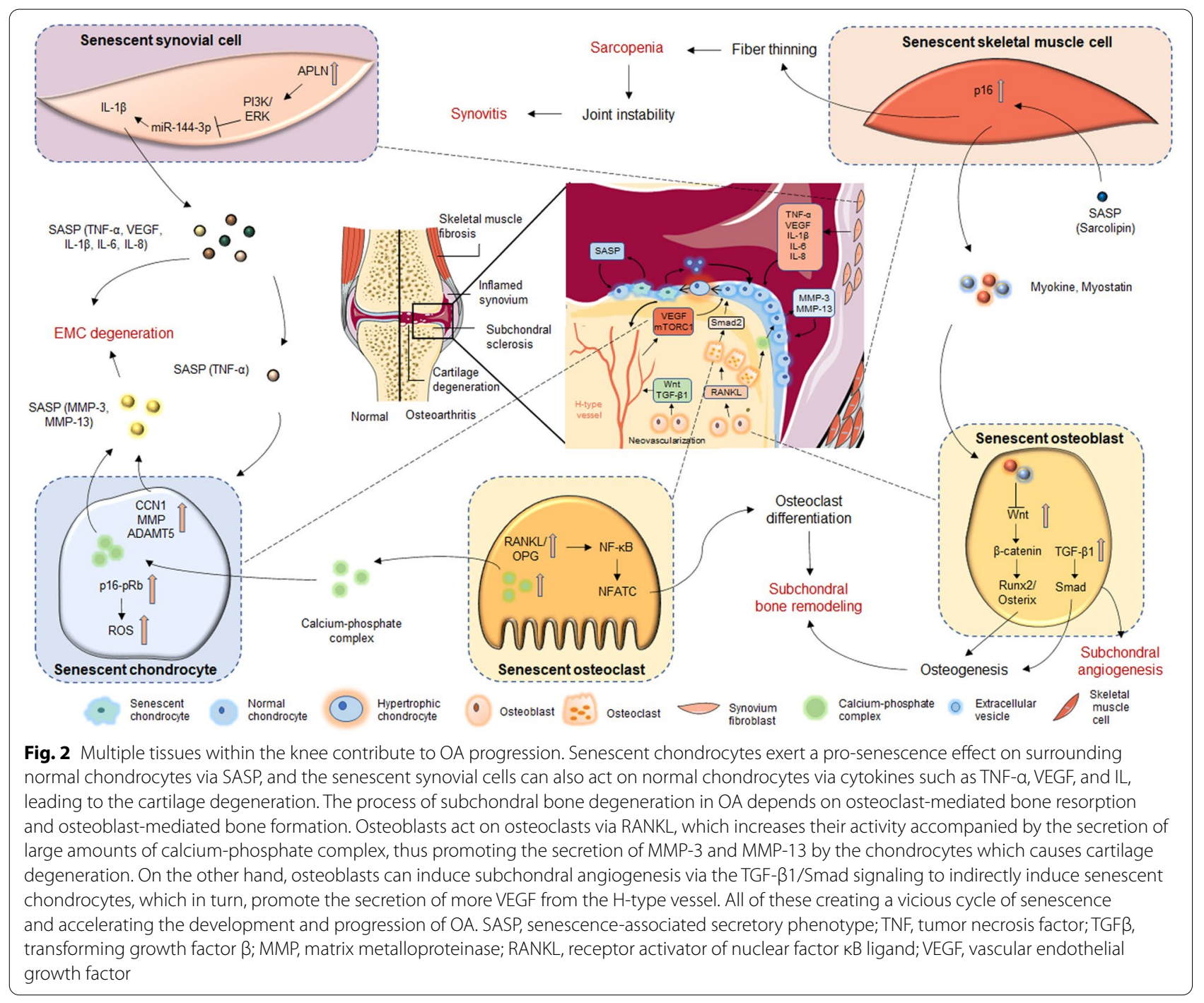

putative kinase 1 (PINK1), a mitophagy-associated protein, has been found to be highly expressed in cartilage of OA patients and in mouse models of monosodium iodoacetate (MIA)-induced OA [77]. In addition, overexpression of parkin RBR E3 ubiquitin protein ligase (PRKN) reduces ROS production and chondrocyte apoptosis by removing dysfunctional mitochondria [78]. PINK1 and PRKN regulate mitophagy through the SIRT3-PINK1-PRKN signaling pathway, thereby delaying chondrocyte senescence [77, 78]. In addition, metformin has been found to act as an activator of the SIRT3-PINK1-PRKN signaling pathway and maintain chondrocyte homeostasis by regulating mitophagy [79]. These findings highlight the important role of the SIRT3PINK1-PRKN signaling pathway in mitophagy and the maintenance of chondrocyte homeostasis, which provides a new direction for the treatment of OA.

\section{Skeletal cell senescence contributes to $O A$}

Increasing evidence has found that senescent cells exist in many tissues including cartilage, subchondral bone, and synovium of OA patients whom undergoing joint replacement. By studying a mouse strain (the p16-3MR transgenic mouse) that selectively develops senescent cells, Jeon et al. found that senescent cells accumulate in the articular cartilage, subchondral bone, and synovium in posttraumatic OA mouse model [80]. However, they did not further investigate the functional implications of these cells in OA development and progression. Senescent cells exhibit a typical SASP, which is observed in OA tissues and synovial fluid at high levels (Fig. 2). In this section, we review our current understanding of senescence in the skeletal cells and their cross-talk with each other within joints (Fig. 3). 


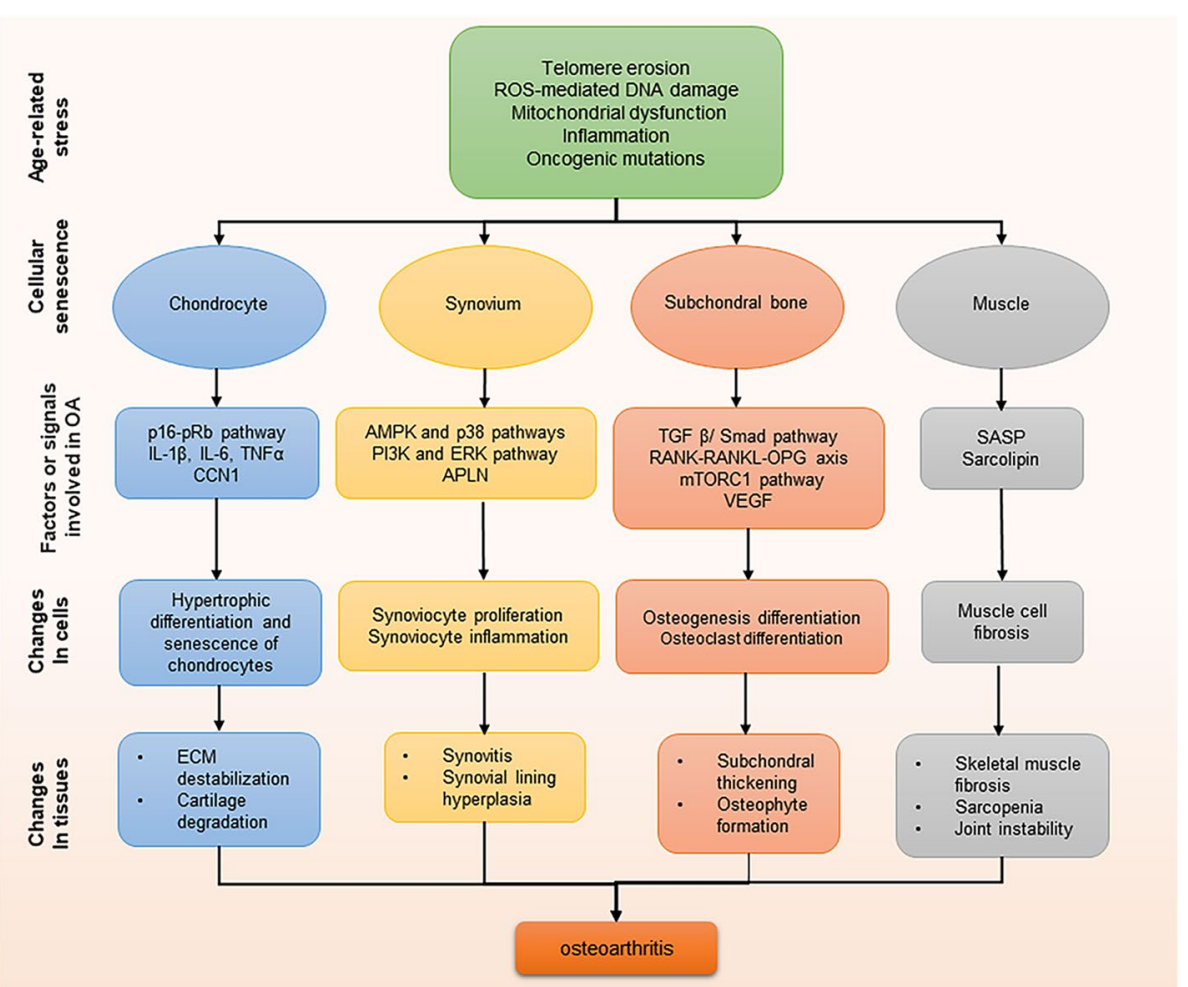

Fig. 3 Associations between senescence and OA in different tissues. A variety of aging-related factors induce cellular senescence within joint tissues. These senescent cells in different tissues can lead to common changes in OA through the SASP or related signaling pathways. ROS, reactive oxygen species; IL, Interleukin; TNF, tumor necrosis factor; CCN1, Cellular communication network factor 1; ECM, extracellular matrix; AMPK, AMP-activated protein kinase; APLN, Adipokine apelin; PI3K, Phosphatidylinositol 3-kinase; RANKL, Receptor activator of nuclear factor KB ligand; VEGF, Vascular endothelial growth factor; TGF $\beta$, transforming growth factor $\beta$; SASP, senescence-associated secretory phenotype

\section{Chondrocytes}

Chondrocytes are unique cells in articular cartilage (AC) and are solely critical for the production and turnover of the extracellular matrix (ECM), which accounts for 95\% of the AC [81]. The balance between the synthesis and degradation of matrix components in $\mathrm{OA}$ is an important factor in determining pathological progression.

Repeated mechanical trauma and oxidative stress are the two major contributing factors for establishing the chronic inflammatory microenvironment which triggers chondrocytes senescence [7]. Senescent chondrocytes acquire a secretory phenotype, releasing proinflammatory cytokines, vascular growth factors, and catabolic enzymes, which damage the stability of the ECM, thus initiating OA progression. This process is confirmed by an animal study showing that injection of senescent chondrocytes into the joints mimicked cartilage damage, similar to that observed in OA mice [82]. In contrast, removing senescent cells was demonstrated to reduce articular cartilage damage and pain in posttraumatic mouse models in another study [83]. These observations are largely explained by the fact that the acquisition of the SASP by senescent cells can change the joint microenvironment and thereby dictating the neighboring cells to undergo cell senescence. Additionally, p16 seems to be the most significant mediator and/or marker of senescent chondrocytes through the p16-pRb pathway, and downregulation of this gene has been shown to restore the normal function of OA chondrocytes [84].

On the other hand, senescent chondrocytes are unable to fold proteins properly. A misfolded protein, namely, the amyloid protein, can be detected in the cartilage of OA patients and has been shown to promote abnormal gene expression, mitochondrial dysfunction and cell death, thus affecting the energy metabolism of chondrocytes in patients with OA [85]. Mitochondria are the engines of cellular metabolism. Studies have shown that mitochondrial dysfunction was characterized by decreased expression of SIRT1 which was involved in mitochondrial biogenesis, and reduced expression of nuclear respiratory factors 1 and 2 (NRF1 and NRF2), which regulated antioxidant gene expression [86]. In addition, it was shown that the deletion of SIRT1 in cartilage aggravated the pathogenesis of OA [87]. Considering 
the results of the above studies, we conclude that chondrocyte senescence and OA are mutually reinforcing processes in OA initiation and progression.

SASP secreted by the senescent chondrocytes in OA play a negative role in regulating healthy neighboring chondrocytes via a paracrine mechanism [46, 88]. Recent studies have found that in addition to SASP, senescent cells are capable to secrete more extracellular vesicles when compared with the normal cells [89]. In addition, the secreted extracellular vesicles dictate the normal cell to undergo senescence via a paracrine manner and forming a vicious circle that might inhibit the cartilage formation [88]. In addition, a recent study has found that cell surface protein that mediates cellular communication such as cellular communication network factor 1 (CCN1) is increased in chondrocytes of OA patients. Inhibition of this protein could slow down the senescence of chondrocyte and reduce the production of MMPs and proinflammatory factors, thus protecting the articular cartilage [90]. These studies suggest that proteins mediating cellular communication may be considered as new targets for the intervention of $\mathrm{OA}$.

Subchondral bone In recent years, the role of subchondral bone in the pathogenesis of OA has gained increasing interest. Subchondral bone undergoes different pathological changes during the development of $\mathrm{OA}$, in which subchondral bone wear occurs in the early stage, while the typical pathological changes in the late stage are subchondral bone sclerosis [91]. A recent study has suggested that the alteration of subchondral bone structure is the main cause of OA in animal models [92]. Fang et al. also found that early damage to subchondral bone (reduction of bone volume) occurs prior to cartilage degeneration and osteophyte formation, whereas in the late-stage of OA, this damage presents as subchondral bone sclerosis in mouse models, which is consistent with the typical pathology of patients with OA [91].

The pathological changes of subchondral bone in different stages of $\mathrm{OA}$ involve bone remodeling. Bone remodeling is highly relied on osteoclast-mediated bone absorption, osteoblast-mediated bone formation, and the interaction with osteocytes, which are embedded in the bone matrix (Table 2). In early-stage OA, the thickening of the calcified cartilaginous layer reduces the load on subchondral bone, and this reduction increases the ratio of receptor activator of nuclear factor $\mathrm{\kappa B}$ ligand (RANKL) to osteoprotegerin (OPG) protein, thus promoting the formation of osteoclasts and enhancing bone resorption [95-97]. During subchondral bone degeneration, osteoclast activity is increased along with the secretion of a large amount of calcium-phosphate complex, thereby promoting the chondrocytes to secrete matrix metalloproteinase (MMP-3 and MMP-13) catabolic enzymes that cause cartilage degeneration [102]. Osteoclasts can also promote the hypertrophic differentiation of chondrocytes by targeting Smad2 [106], which further accelerated the degeneration of articular cartilage. Moreover, increasing evidence has suggested that bone remodeling of subchondral bone is associated with cellular senescence. In older animals, osteocytes and myeloid cells derived from trabecular and cortical bone tissue appear to senescence. In addition, the SASP of these cells is associated with age-related bone loss [80]. Furthermore, p16-positive senescent cells have been found in the subchondral bone marrow in the Anterior cruciate ligament transection (ACLT)-induced OA models [83]. Thus, senescent cells in the subchondral bone may cause physiological changes in the subchondral bone that affect bone remodeling thereby promoting OA progression.

Furthermore, researchers have suggested that there is a positive feedback regulatory mechanism between subchondral $\mathrm{H}$-type vessel formation and chondrocytes that is based on the mTORC1 pathway. In this mechanism, neovascularization of subchondral bone invades cartilage during cartilage degeneration, which stimulates the activation of the mTORC1 pathway by secreting more vascular endothelial growth factors (VEGFs), and the latter exacerbates the structural changes of the subchondral bone and drives OA progression rapidly. The same result was also observed in aged mice, and there was a prominent increase in $\mathrm{H}$-type vessels in the subchondral bone of aged mice $[98,99]$. These results suggested that the microenvironmental changes caused by senescent cells in the subchondral bone may affect the formation of $\mathrm{H}$-type vessels, and $\mathrm{H}$-type vessel formation in subchondral bone is closely related to the development of OA.

Bone remodeling is a process that coupling osteoclastmediated bone resorption and osteoblast-mediated bone formation [107, 108]. Osteoblasts regulate cell mineralization by activating the Wnt signaling pathway, meanwhile, it can also respond to increased mechanical loading by reducing the secretion of sclerostin (SOST) $[109,110]$. The lack of SOST aggravates OA by modulating the turnover and cell apoptosis of the subchondral bone, thus destructing the bone homeostasis $[100,101]$. In addition, researchers have shown that osteoblasts can induce subchondral angiogenesis via the TGF- $\beta 1 / \mathrm{Smad}$ axis to indirectly affect the chondrocytes $[93,94]$. Thus, inhibiting the damage to subchondral bone at the early stage via these pathways may be considered a method to treat OA.

Synovium The synovium, which is composed of synovial fibroblasts and macrophages, is one of the main components of joints. Synovial cells secrete fluid to lubricate and 
Table 2 Role of various cells in the pathogenesis of OA

\begin{tabular}{|c|c|c|c|}
\hline Cell types & Molecules or signals involved during $\mathrm{OA}$ & Effect & Refs \\
\hline \multirow[t]{4}{*}{ Chondrocytes } & p16-pRb pathway & $\begin{array}{l}\text { p16 induces senescence in OA chondrocytes via the p16- } \\
\text { pRb pathway }\end{array}$ & [84] \\
\hline & SASP $(I L-1 \beta, I L-6, T N F-a)$ & $\begin{array}{l}\text { Senescent chondrocytes release SASP to destabilize the } \\
\text { ECM, thereby initiating OA progression }\end{array}$ & {$[46,88]$} \\
\hline & CCN1 & $\begin{array}{l}\text { CCN1 signaling aggravates cartilage inflammation and } \\
\text { matrix degradation. }\end{array}$ & [90] \\
\hline & Amyloid protein & $\begin{array}{l}\text { The amyloid protein promotes abnormal gene expression, } \\
\text { mitochondrial dysfunction, and cell death in OA chondro- } \\
\text { cytes }\end{array}$ & [85] \\
\hline \multirow[t]{4}{*}{ Osteoblast } & TGF $\beta 1$; TGF $\beta /$ Smad pathway & $\begin{array}{l}\text { Induce subchondral angiogenesis to indirectly affect } \\
\text { chondrocyte }\end{array}$ & {$[93,94]$} \\
\hline & RANKL & $\begin{array}{l}\text { Stimulate osteoclast differentiation and enhance bone } \\
\text { resorption }\end{array}$ & [95-97] \\
\hline & VEGF & Stimulate angiogenesis to indirectly affect chondrocyte & {$[98,99]$} \\
\hline & SOST & $\begin{array}{l}\text { The lack of SOST aggravate OA by producing different } \\
\text { degrees of apoptosis in the body to affect subchondral } \\
\text { bone homeostasis }\end{array}$ & {$[100,101]$} \\
\hline \multirow[t]{2}{*}{ Osteoclast } & Calcium-phosphate complex & $\begin{array}{l}\text { Promotes the secretion of MMP-3, MMP-13 by chondro- } \\
\text { cytes, leading to cartilage degeneration }\end{array}$ & [102] \\
\hline & TGF $\beta /$ Smad pathway & Promote the hypertrophic differentiation of chondrocyte & {$[93,94]$} \\
\hline \multirow[t]{2}{*}{ Osteocyte } & RANKL/OPG; RANK-RANKL-OPG system & $\begin{array}{l}\text { Induce osteoclast differentiation and enhance bone resorp- } \\
\text { tion }\end{array}$ & [95-97] \\
\hline & VEGF; mTORC1 pathway & $\begin{array}{l}\text { Indirect regulation of chondrocytes by stimulating angio- } \\
\text { genesis }\end{array}$ & [93] \\
\hline Synovium fibroblasts & AMPK and p38 pathways; APLN; PI3K and ERK pathway & $\begin{array}{l}\text { Knockdown of APLN expression could ameliorated changes } \\
\text { in OA cartilage severity }\end{array}$ & [103] \\
\hline \multirow[t]{2}{*}{ Musculoskeletal cells } & Sarcolipin & $\begin{array}{l}\text { Sarcolipin secreted by senescent muscle cells promote } \\
\text { skeletal muscle fibrosis and ultimately lead to sarcopenia, } \\
\text { thereby accelerating the development of OA in terms of } \\
\text { biomechanical mechanisms }\end{array}$ & [104] \\
\hline & Myokine, myostatin;Wnt/ $\beta$-catenin signaling & $\begin{array}{l}\text { The muscle released myokine, myostatin inhibits osteogenic } \\
\text { differentiation by suppressing Wnt/B-catenin signaling }\end{array}$ & [105] \\
\hline
\end{tabular}

SASP senescence-associated secretory phenotype, IL interleukin, TNF tumor necrosis factor, TGF $\beta$ transforming growth factor $\beta$, CCN1 cellular communication network factor 1, MMP matrix metalloproteinase, RANKL receptor activator of nuclear factor KB ligand, VEGF vascular endothelial growth factor, OPG osteoprotegerin, AMPK AMP-activated protein kinase, APLN adipokine apelin, PI3K phosphatidylinositol 3-kinase

nourish the joint. In clinical practice, patients with OA often suffer from synovial inflammation. Senescent cells have also been found in the synovium of OA patients [111]. In addition to senescent chondrocytes, the senescence of synovial fibroblasts is also thought to be the cause of OA. It has been demonstrated that more p16-positive senescent synovial fibroblasts are detected in synovial tissue samples from OA tissues compared with normal synovial tissue [112]. Furthermore, transplantation of senescent synovial fibroblasts into the knee of mice has been found to induce cartilage erosion and osteophyte formation [82], suggesting that senescent synovial cells play a key role in altering the intra-articular microenvironment thereby promoting OA pathogenesis. Mechanistically, senescent synoviocytes not only affect the quality of the synovium, but also increase the expression of IL-1 $\beta$, IL-6, IL-8, TNF$\alpha$, and VEGF, which create an inflammatory microenvironment that favors cartilage degeneration [113]. TNF- $\alpha$ as proinflammatory mediator is crucial in regulating cartilage matrix degradation via upregulating the expression of matrix degradation enzymes such as MMPs and ADAMTS [114]. Even in the absence of an acute infection, the levels of inflammatory mediators in the joints of older OA patients usually increase with age [115]. .Although it is still unclear whether synovial changes are primary or secondary to OA, cross-talk between senescent skeletal cells and synovium is likely to be true. Synoviocytes induce cartilage destruction by secreting enzymes and inflammatory mediators that promote cartilage dissolution, thus aggravating synovial inflammation and forming a vicious cycle [116]. This cycle was exemplified in a recent study showing that adipokine apelin (APLN) in synovial fibroblasts of patients with OA regulates the activity of cartilage, synovium, bone, and various immune cells, and is related to the pathogenesis of OA [103]. Mechanistically, APLN inhibits the expression of miRNA-144-3p and stimulates 
the expression of IL-1 $\beta$ by activating the PI3K and ERK pathways [103]. Thus, downregulating the expression of APLN may ameliorate changes in OA cartilage severity.

Musculoskeletal cells Decreasing activity and muscle wasting would be caused by OA pain, and we have recently demonstrated that knee muscle atrophy is a risk factor for development of knee osteoarthritis [117]. Adult muscle stem cells in skeletal muscle are called satellite cells which are mainly responsible for muscle repair and regeneration in injured and aging muscles. However, the repair and regenerative function of satellite cells decreases with aging [118]. It has been found that when injured, these cells accelerate into senescence losing their repair and regenerative functions [17]. A recent study has shown that the implantation of senescent cells into the healthy skeletal muscle resulted in an increase of p16-positive muscle cells, along with the thinning of muscle fiber [119]. Factors in SASP such as sarcolipin have also been shown to promote skeletal muscle fibrosis and ultimately lead to sarcopenia [104]. Sarcopenia due to senescent skeletal muscle cells may also be involved in the development of OA from a biomechanical mechanism, e.g., causing joint instability or secondary synovitis. Furthermore, the muscle-released myokine, myostatin, is demonstrated to inhibit osteogenic differentiation by suppressing the Wnt/ $\beta$-catenin signaling [105]. These findings together suggest that the senescence of musculoskeletal cells via cross-talk with synovium fibroblasts, chondrocytes, and osteoblast, is fundamental for $\mathrm{OA}$ initiation and progression.

\section{Targeted therapies for age-related $\mathrm{OA}$}

As mentioned above, senescent cells in joints contribute to the senescence of neighboring cells through the SASP in the form of paracrine signaling. Senescent cells further promote the accumulation of senescent cells through the activation of SCAPs, thereby exacerbating the development of OA. Therefore, local elimination of senescent cells and/or blockade of SASP acquisition are considered promising therapeutic strategies for OA. A summary utilizing these principles to delay the progression of OA can be found in Fig. 4 and Table 3.

Recently, according to the inflammatory mechanisms, cell aging, cartilage metabolism, subchondral bone remodeling, and peripheral pain pathways, a series of therapies have been developed against OA [128, 129]. Senolytics and Senomorphics are promising therapeutic agents that slow the progression of OA by targeting its pathogenesis [130]. Senolytics induces the apoptosis of senescent cells and Senomorphics blocks the paracrine secretion characteristic of the SASP to eliminate or delay the adverse effects of senescent cells in the development of OA [131]. Senolytics is a drug selectively eliminating senescent cells. Dasatinib, the first generation of Senolytics, which is a chemotherapy drug used to treat leukemia, and later, it was developed as a therapeutic strategy

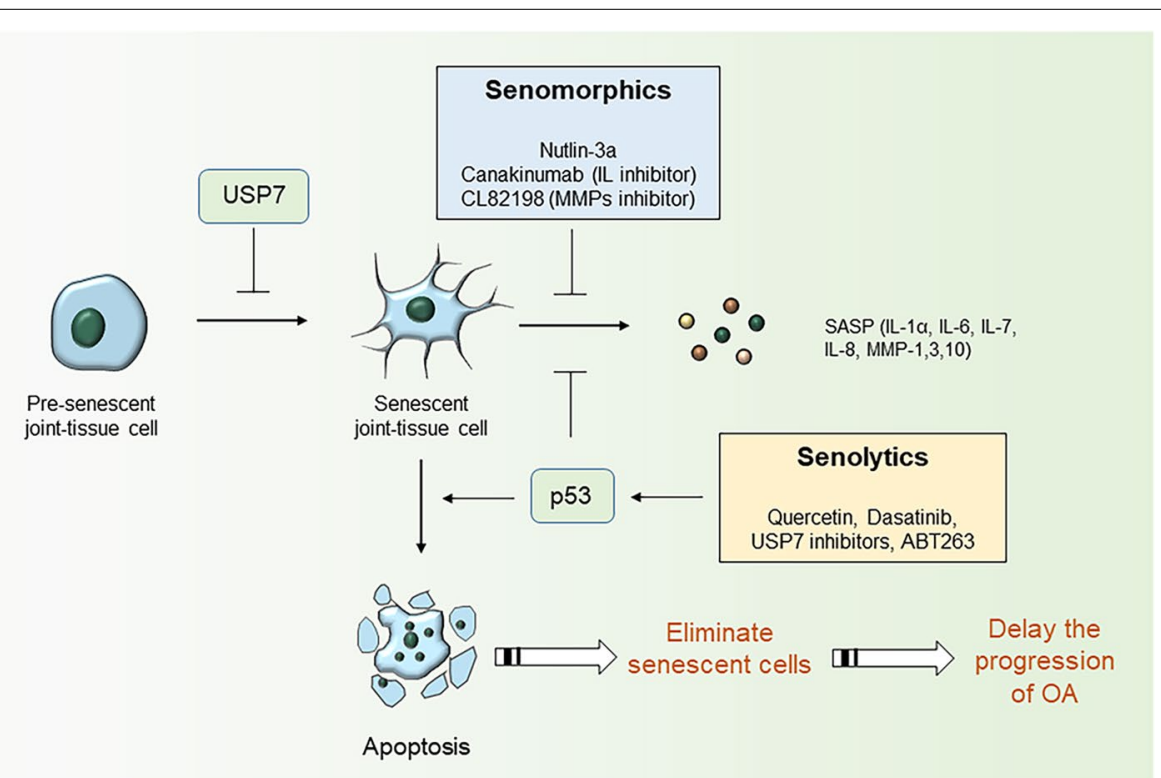

Fig. 4 Targeted therapies for senescent cells in joint tissues. Senolytics (Quercetin, Dasatinib, USP7 inhibitors, ABT263) by inducing the apoptosis of senescent cells and Senomorphics (Nutlin-3a, Canakinumab, CL82198) by blocking the paracrine secretion of senescent secretory phenotype (SASP) to delay the effect of senescent cells on the development of OA. Senolytics induce apoptosis in senescent cells by restoring the activity of p53. Senomorphics inhibit the secretion of SASP to attenuate the pro-senescence effect of senescent cells on surrounding cells 
Table 3 Targeted therapies for OA

\begin{tabular}{|c|c|c|c|}
\hline Categories of drugs & Compound & Effects in OA & Refs \\
\hline \multirow[t]{3}{*}{ Senolytics } & Quercetin and Dasatinib & Selectively induce apoptosis in senescent cells while not affecting proliferating cells & [120-122] \\
\hline & USP7 inhibitors & Activate the apoptotic program after the stabilization of p53 to kill senescent cells & [123] \\
\hline & ABT263 (Navitoclax) & $\begin{array}{l}\text { Eliminate senescent cells, reduce the expression of inflammatory cytokines and } \\
\text { promote the maintenance of chondrogenic phenotypes in vitro }\end{array}$ & [111] \\
\hline \multirow[t]{3}{*}{ Senomorphics } & Nutlin-3a & Increase p53 levels and attenuate the secretory phenotype of senescent cells & {$[124,125]$} \\
\hline & Canakinumab & Inhibition of IL-1 $\beta$ expression delays the progression of OA & [126] \\
\hline & CL82198 & Reduce the severity of OA by inhibiting chondrocyte death & [127] \\
\hline
\end{tabular}

eliminating senescent cells. Research has shown that quercetin and Dasatinib selectively induce the apoptosis of senescent cells but do not affect proliferating cells [120]. In another study, transplantation of senescent cells into young mice resulted in physical dysfunction in the mice. However, treating these mice with quercetin and dasatinib mitigated the harmful effects caused by senescent cell transplantation [121, 122]. Mouse double minute 2 (MDM2) is one of the most important inhibitors of $\mathrm{p} 53$. When these two proteins are combined, they degrade the p53 protein and reduce its activity. A study has shown that ubiquitin-specific peptidase 7 (USP7) was a novel target of Senolytics, because it isolated p53 from MDM2, thereby inhibiting the MDM2 interaction with p53 in mice, and selectively eliminating senescent cells by restoring p53 activity. Furthermore, this study implicated that injection of USP7 inhibitors into the joint of OA rats inhibited cartilage degeneration, thereby slowing the progression of OA [123]. Recently, a study evaluated the ability of the senolytic drug ABT263 (Navitoclax) to clear senescent cells. Chondrocytes were obtained from OA patients for use in experiments performed in vitro and in a DMM rat model for in vivo experiments to evaluate the effect of ABT263. The results showed that ABT263 reduced the expression of inflammatory cytokines in OA cartilage cultures and promoted cartilage matrix aggregation by inducing the apoptosis of senescent cells. Intra-articular injection of ABT263 attenuated bony lesions in cartilage and subchondral bone of rats with DMM-induced OA [111]. Considering the correlation between SASP factor expression and the development of OA, inhibition of SASP molecule secretion is a promising therapeutic approach. One study has confirmed that Nutlin-3a, a Senomorphics, increases p53 expression and attenuates the SASP. Therefore, Nutlin-3a prevents OA development and cartilage destruction by inhibiting MDM2 expression and activating the apoptotic program to kill senescent cells after p53 stabilization [124, 125]. Another study found that in an experimental group receiving canakinumab, an inhibitor of IL- $1 \beta$, the incidence of knee and hip replacements was lower than that in the placebo-treated control group [126]. Additionally, some researchers have used the MMP13 selective inhibitor CL82198 to treat meniscal-ligamentous injuryinduced OA mouse models. They found that CL82198 reduced the severity of $\mathrm{OA}$ by inhibiting chondrocyte death [127]. These findings suggested that Senomorphics also delay the progression of OA.

In conclusion, the removal of senescent cells and/or suppression of the SASP subsequently slow the progression of OA. Therefore, targeting senescent cells and their SASP may provide a novel strategy for the treatment of age-related diseases such as OA.

\section{Experimental animal models for the research of $O A$ and aging}

Experimental animal models are essential tools for exploring the mechanism of OA development and progression. The mechanisms between $\mathrm{OA}$ and cellular senescence are complex. Therefore, the establishment of an ideal animal model is particularly important for the study of OA pathogenesis and/or evaluation of the curative effect. A summary of the animal models currently used for aging and OA studies are shown in Table 4 and Table 5.

\section{Spontaneous model of $O A$}

The spontaneous model does not need intervention and is less subject to external interference. It avoids the influence caused by operation error as much as possible and is closer to the OA process of humans. However, due to the slow progress, the application in the research is limited. There is a spontaneous model of OA, STR/ort mice, which spontaneously develop OA in early life and show many characteristics of human OA [132]. Furthermore, Malaise et al. firstly showed that senescence-accelerated mouse-prone (SAMP8) mice developed OA spontaneously [134]. The use of these spontaneous OA mice can avoid interference from external factors, and thus, the pathology of age-related OA can be more accurately mimicked. 
Table 4 The advantages and disadvantages of experimental animal models for OA and aging

\begin{tabular}{|c|c|c|}
\hline Exp. animal models & Advantages & Disadvantages \\
\hline Spontaneous model & $\begin{array}{l}\text { Mostly similar to the characteristics of human aging, omit- } \\
\text { ting surgery, or drug delivery steps }\end{array}$ & $\begin{array}{l}\text { Long feeding period, poor health, high mortality, and large } \\
\text { individual differences }\end{array}$ \\
\hline Drug-induced model & $\begin{array}{l}\text { Little trauma, no traumatic synovitis interference, simple } \\
\text { operation }\end{array}$ & $\begin{array}{l}\text { Cannot accurately simulate the chronic changes of human } \\
\text { osteoarthritis }\end{array}$ \\
\hline Surgical induction model & $\begin{array}{l}\text { Short period of establishing model time, high success rate, } \\
\text { and high repeatability }\end{array}$ & $\begin{array}{l}\text { Complicated operation, large trauma; hemorrhage and } \\
\text { traumatic synovitis easily affect the biochemical metabolism } \\
\text { of cartilage and synovium in the early stage of OA }\end{array}$ \\
\hline Transgenic model & Accurate modification to facilitate the study of mechanism & The model establishing process is long and costly. \\
\hline
\end{tabular}

Table 5 Experimental animal models for the research of $O A$ and aging

\begin{tabular}{llll}
\hline Exp. animal models for OA & Refs & Exp. animal models for aging \\
\hline $\begin{array}{l}\text { Spontaneous model of OA } \\
\text { STR/ort mice }\end{array}$ & {$[132]$} & Transgenic mouse strains \\
SAMP8 mice & {$[134]$} & p16 ${ }^{\text {LUC }}$ knock-in mice & Cdkn2aluc/luc mice \\
Surgically induced OA models & & p16-3MR transgenic mice \\
ACLT & {$[135]$} & SAMP8 mice \\
DMM & {$[137]$} & D-Galactose-induced model \\
Transgenic and inbred mouse strains & & Slc25a46- knockout mice \\
ADAMTS5-knockout mice & {$[140]$} & \\
SIRT1-knockout mice & {$[87]$} & \\
JNK-knockout mice & {$[36]$} & \\
AMPK a1-knockout mice & {$[141]$} & \\
Pitx1-knockout mice & {$[71]$} & \\
Chemically induced models & & \\
Injections of MIA & {$[77,142,143]$} & \\
\hline
\end{tabular}

SAMP senescence-accelerated mouse-prone, ACLT anterior cruciate ligament transection, DMM destabilization of the medial meniscus, SIRT1 Sirtuin 1, JNK Jun $\mathrm{N}$-terminal kinases, AMPK AMP-activated protein kinase, Pitx 1 pituitary homeobox 1, MIA, monosodium iodoacetate

\section{Inductive model and transgenic animal model of $O A$}

Inductive models of $\mathrm{OA}$ are established through surgical and chemical interventions. Surgically induced OA models were usually established using ACLT or medial meniscus instability (DMM). These methods were firstly used in mice by the Kamekura group [135]. Mechanical instability-induced models establish models with slower OA progression, which is comparable to the development of human OA. The DMM model simulates clinical meniscus or ligament injury, which is a known risk factor for the onset of human OA. This model has become the gold standard for OA research [137].

With the development of transgenic technology, transgenic and inbred mouse strains are particularly useful models for studying the molecular mechanisms of OA development. The DMM model has been established with transgenic mice to evaluate the effect of specific genes on the development and progression of OA. Glasson et al. first reported that single-gene deletions can reduce cartilage destruction in an animal model of OA. They demonstrated that the severity of cartilage damage in ADAMTS5-knockout mice was significantly lower than that in wild-type mice [140]. Recently, using the same approach, Mao et al. found that the deletion of SIRT1 in cartilage exacerbated the pathogenesis of OA by activating p53/p21-mediated cellular senescence and increasing SASP-related secretion levels [97]. .Furthermore, Loeser et al. found that the deletion of JNK1 or JNK2 can aggravate the development of age-related OA by increasing the number of senescent cells in JNK-knockout mice [36]. In a recent study, AMP-activated protein kinase (AMPK) $\alpha 1$-knockout mice were used to study the effects of metformin on the progression of OA [106]. The results showed that the DMM-induced OA phenotype was accelerated in AMPK $\alpha 1-K O$ mice. Metformin has a protective effect on cartilage and can reduce the progression of $\mathrm{OA}$, but metformin lost its protective effect in the AMPK $\alpha 1-\mathrm{KO}$ mice, which suggests that the cartilage protection of metformin is mediated by AMPK signaling [106]. Furthermore, a recent study found that activation 
of AMPK resulted in decreased expression of the SASP in senescent cells [144]. Therefore, we hypothesize that the protective effect of metformin on cartilage in OA patients may be due to the activation of the AMPK pathway and the reduction of the secretion in SASP-related secretions from senescent chondrocytes. AMPK $\alpha 1-K O$ mice may also be useful in the study of aging and OA. Pitx1 plays a role in regulating lower limb development [141]. In consideration of the characteristics of uneven cartilage degeneration in OA, Zhao et al. first proposed a self-controlled model to investigate the effects of Pitx1 on chondrocytes of OA cartilage. The results revealed that downregulation of Pitx1 was an important cause of cartilage degeneration and decreased chondrocyte function and chondrocyte senescence in the medial tibial plateau of OA patients [71]. This study found that downregulation of Pitx1 caused chondrocyte senescence in the OA patients; thus, Pitx1-knockout mice may also be a suitable model for aging and OA studies.

Establishing chemically induced models involves injections of inflammatory agents such as immunotoxins, collagenase, papain, or MIA into the knee [142, 145, 146]. The MIA model has become a standard for modeling OA models in animals. Intra-articular injection of MIA destroys glycolysis in chondrocytes, leading to chondrocyte death, neovascularization, subchondral osteonecrosis, and collapse, as well as inflammation that mimics that of OA [142, 143]. However, some studies have reported that abnormal glycolysis can lead to cellular senescence [147]. Therefore, intra-articular injection of MIA may aggravate the development of OA by accelerating cellular senescence in the joint.

\section{Experimental animal models of aging}

Monitoring aging in vivo remains challenging in experiments. Burd et al. described a luciferase knock-in mouse $\left(\mathrm{p} 16^{\mathrm{LUC}}\right)$ that can specifically reveal the expression of p16 and therefore can be used for aging-related studies [133]. To test whether senescent cells aggravate the development of OA. Malaise et al. established Cdkn2a ${ }^{+/}$ luc[+/luc] and Cdkn2aluc/luc transgenic mice, in which the Cdkn2a $a^{\text {luc/luc }}$ mice lack p16 expression. They found that the loss of p16 expression after OA induction had a significant protective effect on OA-driven cartilage degradation [134]. Furthermore, another study demonstrated that p16-positive cells play deleterious roles in ACLTinduced OA joints through p16-3MR transgenic mice, which specifically track and remove senescent cells [83]. In addition, the mice mentioned above and the D-Galactose-induced accelerated aging models can be used in the study of age-related diseases or anti-aging therapeutic intervention studies $[136,138]$. Recently, a mouse model with the Slc25a46 gene knocked out was developed using CRISPR/Cas9 gene editing to mimic some of typical aging phenotypes in humans, and it was an effective animal model for pathological study of segmental aging based on mitochondrial theory [139]. The Slc25a46-KO mouse is characterized by a life span of no more than 2 months, skeletal muscle dysfunction, and reduced exercise capacity; thus, this animal model can be used in the study OA because it simulates the aging state of humans realistically.

\section{The future direction of aged-related $\mathrm{OA}$ research}

Research on age-related OA over the past 20 years has transitioned from identifying phenotypes to studying the genetic and epigenetic signaling behind these phenotypes. Cellular senescence and $\mathrm{OA}$ are interactive processes involving a complex network of intracellular signaling pathways. In Fig. 5, we recapitulate a few key processes that have been discovered during the past 20 years, which contribute to the understanding of how cellular senescence is involved in the study of OA.

To understand the underlying mechanism between cellular senescence and OA, many animal models have been introduced. Subsequently, transgenic mice have also been studied in the field of aging-related OA. The development of transgenic mouse models that selectively eliminate senescent cells has confirmed that senescent cells play important roles in the development of OA. For example, the p16-3MR transgenic mice described above carry the p16INK4a (Cdkn2a) promoter, which drives the expression of a fusion protein containing the structural domains of synthetic luciferase and fluorescent protein [83, 133], thereby allowing tracking of p16-positive cells.

Using appropriate animal models of aging and OA might provide better evidence to improve our understanding of the underlying mechanisms of age-related OA. Furthermore, studies are required in which OA can be considered a "whole organ" disease and show the cross-talk between senescent skeletal cells and macrophage, which is of great importance. Using these models, we can prevent, delay, or reverse cellular senescence within the joints, possibly, by using Senolytics and Senomorphics to halt the development of OA [120, 148, 149].

\section{Conclusion}

Over time, cellular senescence in joint tissue is inevitable. The evidence suggests that senescent cells may be involved in the onset and progression of OA through the SASP and/or altering the intra-articular joint environment. Senescence is closely associated with OA, and the pathogenesis of age-related OA involves all components of the joint, including articular cartilage, subchondral bone, synovium, and muscles. Senescent skeletal cells may influence the development of OA through cross-talk 


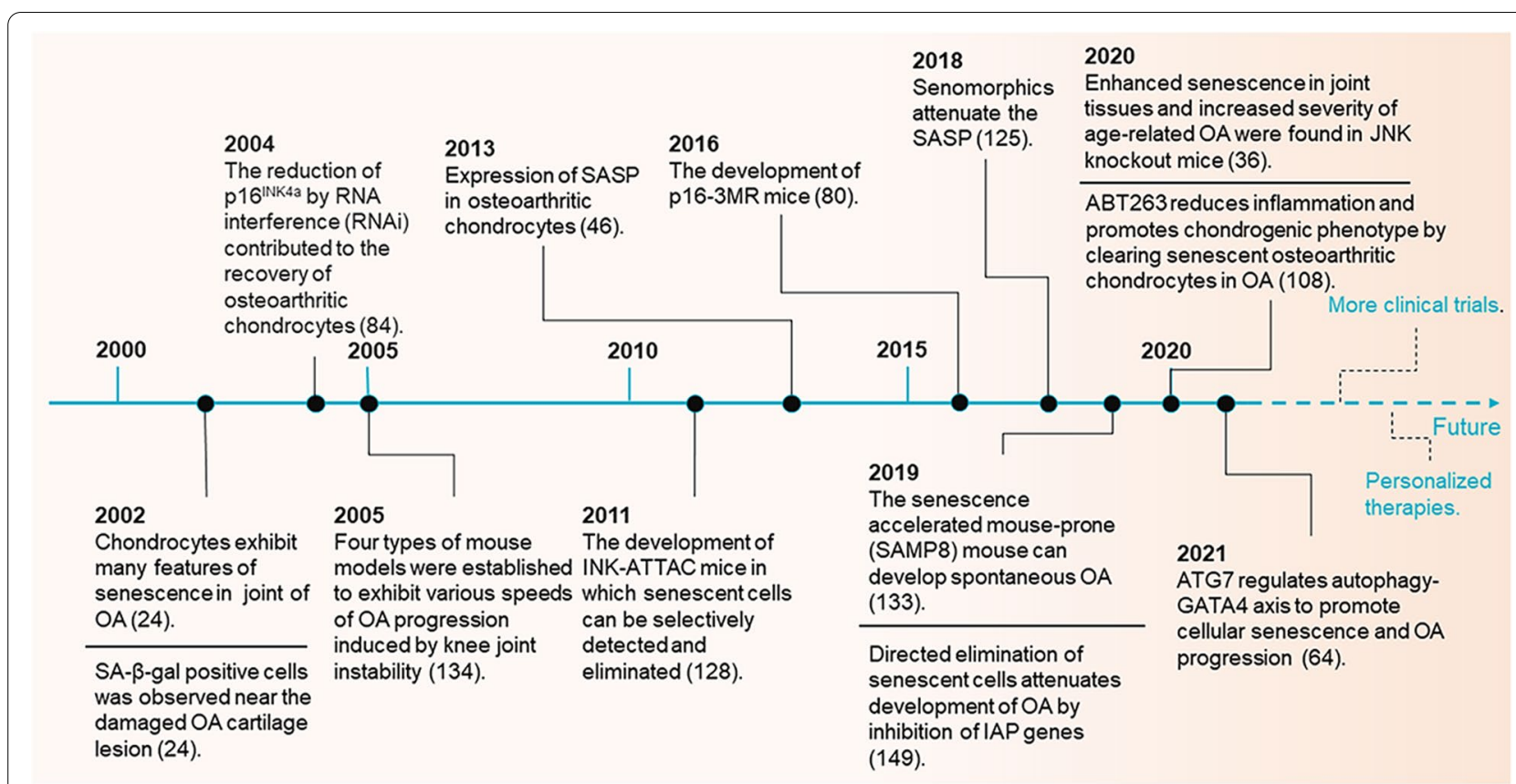

Fig. 5 Timeline of age-related OA research over the past 20 years. Key discoveries in OA from the perspective of cellular senescence are highlighted. Since 2002, the mechanism of chondrocyte aging on the pathogenesis of OA has been first reported, and by 2021, a variety of anti-aging drugs have been discovered to treat OA. The continuous update of treatment methods mainly depends on the continuous in-depth understanding of the pathogenesis of OA by researchers

with synovial cells. In addition, the interaction of senescent cells in joint tissue might disrupt intra-articular homeostasis, leading to exacerbation of OA. Therefore, it is suggested that the cross-talk between senescent skeletal cells and synovial cells within joints is critical for initiating OA. However, further research is needed to determine the precise mechanism(s) by which senescence induces acquisition of these specific phenotypes. If we can identify the cells that are the major risk factors for $\mathrm{OA}$, then administration of a specific drug eliminating these senescent cells may become a new method of treating $\mathrm{OA}$, with the potential to prevent and treat it in the near future. Recently, several therapeutic drugs including Senolytics and Senomorphics have been developed and tested in a panel of cells or animals. More evidence has shown that targeting senescent cells will shed light on the treatment of age-related chronic diseases such as OA.

\footnotetext{
Abbreviations

AC: Articular cartilage; ATG: Autophagy-related gene; APLN: Adipokine apelin; ACLT: Anterior cruciate ligament transection; AMPK: AMP-activated protein kinase; COL10A1: Collagen type X; COL2A1: Collagen type II; CCN1: Cellular communication network factor 1; DMM: Destabilization of the medial meniscus; ECM: Extracellular matrix; GM-CSF: Granulocyte macrophagecolony stimulating factor; HSV-TK: Herpes simplex virus 1 thymidine kinase; IL-1 B: Interleukin-1 13; L-6: Interleukin-6; JNK: Jun N-terminal kinase; MSCs: Mesenchymal stem cells; MAPK: Mitogen-activated protein kinase; MDM2: Mouse Double Minute 2; MIA: Monosodium iodoacetate; MP : Microparticle; mTOR: Mechanistic target of rapamycin kinase; NRF: Nuclear respiratory
}

factors; NF-KB: Nuclear factor KB; OA: Osteoarthritis; OPG: Osteoprotegerin; PTOA: Posttraumatic osteoarthritis; PI3K: Phosphatidylinositol 3-kinase; Pitx1: Pituitary homeobox 1; PINK1: PTEN-induced putative kinase 1; PRKN: Parkin RBR E3 ubiquitin protein ligase; ROS: Reactive oxygen species; RTL: Relative telomere length; RANKL: Receptor activator of nuclear factor KB ligand; SASP: Senescence-associated secretory phenotype; SA- $\beta$-gal: Senescence-associated beta-galactosidase; SAMP: Senescence-accelerated mouse-prone; SCAPS: Senescent cells anti-apoptotic pathways; SIRT1: Sirtuin 1; SOX9: SRY-BOX transcription factor 9; SOD2: Superoxide dismutase 2; SOST: Sclerostin; TGF $\beta$ : Transforming growth factor $\beta$; USP7: Ubiquitin-specific peptidase 7; VEGF: Vascular endothelial growth factor.

\section{Acknowledgements}

We acknowledge servier medical art (https://smart.servier.com) for providing some elements included in Fig. 2.

\section{Authors' contributions}

HTZ and NL conceived and designed the study. CJW, RXL, and SWH searched the literature, interpreted the data, and wrote the manuscript. CJW made the figures. ZGZ, ZYL, WT, JCZ, YKZ, YZ, and JY helped in the discussion and editing during writing of the manuscript. All authors have read and approved the final version of the manuscript.

\section{Funding}

This work was supported by the National Natural Science Foundation of China (82072470, 81871809, 81672224), the Natural Science Foundation of Guangdong Province (2021A1515012154, 2017A030313556), Funding by Science and Technology Projects in Guangzhou (202102010069), the Macau Foundation for Development of Science and Technology (0029/2019/A), Youth Talent Support Project of Guangzhou Association for Science \& Technology (X20200301018), Foundation Project of Shenzhen Key Laboratory of Musculoskeletal Tissue Reconstruction and Function Restoration (ZDSYS20200811143752005), and Research Foundation of The Affiliated Shunde Hospital of Jinan University (202101003). 
Availability of data and materials

Not applicable.

\section{Declarations}

\section{Ethics approval and consent to participate}

Not applicable.

\section{Consent for publication}

All of the authors listed have approved the manuscript for publishment.

\section{Competing interests}

The authors declare that they have no competing interests.

\section{Author details}

${ }^{1}$ Department of Bone and Joint Surgery, the First Affiliated Hospital, Jinan University, Guangzhou 510630, Guangdong, China. ${ }^{2}$ Institute of Orthopedic Diseases \& The Bone and Joint Disease institute of Guangdong-Hong Kong-Macao Greater Bay Area, Jinan University, Guangzhou 510630, China

Received: 13 July 2021 Accepted: 14 February 2022

Published online: 28 February 2022

\section{References}

1. Hunter DJ, Bierma-Zeinstra S. Osteoarthritis. Lancet (London, England). 2019;393(10182):1745-59.

2. Prieto-Alhambra D, Judge A, Javaid MK, Cooper C, Diez-Perez A, Arden NK. Incidence and risk factors for clinically diagnosed knee, hip and hand osteoarthritis: influences of age, gender and osteoarthritis affecting other joints. Ann Rheum Dis. 2014;73(9):1659-64.

3. Katz JN, Arant KR, Loeser RF. Diagnosis and treatment of hip and knee osteoarthritis: a review. Jama. 2021;325(6):568-78.

4. Kumar P, Liu C, Hsu JW, Chacko S, Minard C, Jahoor F, et al. Glycine and $\mathrm{N}$-acetylcysteine (GlyNAC) supplementation in older adults improves glutathione deficiency, oxidative stress, mitochondrial dysfunction, inflammation, insulin resistance, endothelial dysfunction, genotoxicity, muscle strength, and cognition: Results of a pilot clinical trial. Clin Transl Med. 2021;11(3):e372.

5. Hunter DJ, Schofield D, Callander E. The individual and socioeconomic impact of osteoarthritis. Nat Rev Rheumatol. 2014;10(7):437-41.

6. Martel-Pelletier J, Barr AJ, Cicuttini FM, Conaghan PG, Cooper C, Goldring MB, et al. Osteoarthritis. Nat Rev Dis Primers. 2016;2:16072.

7. McCulloch K, Litherland GJ, Rai TS. Cellular senescence in osteoarthritis pathology. Aging Cell. 2017;16(2):210-8.

8. Toh WS, Brittberg M, Farr J, Foldager CB, Gomoll AH, Hui JH, et al. Cellular senescence in aging and osteoarthritis. Acta Orthop. 2016;87(sup363):6-14.

9. Farr JN, Khosla S. Cellular senescence in bone. Bone. 2019;121:121-33.

10. Aigner T, Haag J, Martin J, Buckwalter J. Osteoarthritis: aging of matrix and cells--going for a remedy. Curr Drug Targets. 2007:8(2):325-31.

11. Lotz $M$, Loeser RF. Effects of aging on articular cartilage homeostasis. Bone. 2012;51(2):241-8.

12. Xie J, Wang Y, Lu L, Liu L, Yu X, Pei F. Cellular senescence in knee osteoarthritis: molecular mechanisms and therapeutic implications. Ageing Res Rev. 2021;70:101413.

13. Coryell PR, Diekman BO, Loeser RF. Mechanisms and therapeutic implications of cellular senescence in osteoarthritis. Nat Rev Rheumatol. 2021;17(1):47-57.

14. Hayflick L, Moorhead PS. The serial cultivation of human diploid cell strains. Exp Cell Res. 1961;25:585-621.

15. Smith JR, Pereira-Smith OM. Replicative senescence: implications for in vivo aging and tumor suppression. Science (New York, NY). 1996;273(5271):63-7.

16. Loeser RF. Aging and osteoarthritis: the role of chondrocyte senescence and aging changes in the cartilage matrix. Osteoarthr Cartil. 2009;17(8):971-9.
17. Sousa-Victor P, Gutarra S, García-Prat L, Rodriguez-Ubreva J, Ortet L, Ruiz-Bonilla V, et al. Geriatric muscle stem cells switch reversible quiescence into senescence. Nature. 2014;506(7488):316-21.

18. Schwarze SR, Shi Y, Fu VX, Watson PA, Jarrard DF. Role of cyclin-dependent kinase inhibitors in the growth arrest at senescence in human prostate epithelial and uroepithelial cells. Oncogene. 2001;20(57):8184-92.

19. Rochette PJ, Brash DE. Progressive apoptosis resistance prior to senescence and control by the anti-apoptotic protein BCL-xL. Mech Ageing Dev. 2008;129(4):207-14.

20. Ashraf S, Cha BH, Kim JS, Ahn J, Han I, Park H, et al. Regulation of senescence associated signaling mechanisms in chondrocytes for cartilage tissue regeneration. Osteoarthr Cartil. 2016;24(2):196-205.

21. Copp ME, Flanders MC, Gagliardi R, Gilbertie JM, Sessions GA, Chubinskaya $\mathrm{S}$, et al. The combination of mitogenic stimulation and DNA damage induces chondrocyte senescence. Osteoarthr Cartil. 2021;29(3):402-12.

22. Jain D, Cooper JP. Telomeric strategies: means to an end. Annu Rev Genet. 2010;44:243-69.

23. Sfeir A, de Lange T. Removal of shelterin reveals the telomere endprotection problem. Science (New York, NY). 2012;336(6081):593-7.

24. Price JS, Waters JG, Darrah C, Pennington C, Edwards DR, Donell ST, et al. The role of chondrocyte senescence in osteoarthritis. Aging Cell. 2002;1(1):57-65.

25. Fallet $\mathrm{E}$, Jolivet $\mathrm{P}$, Soudet J, Lisby M, Gilson E, Teixeira MT. Lengthdependent processing of telomeres in the absence of telomerase. Nucleic Acids Res. 2014;42(6):3648-65.

26. Fragkiadaki P, Nikitovic D, Kalliantasi $K$, Sarandi E, Thanasoula M, Stivaktakis PD, et al. Telomere length and telomerase activity in osteoporosis and osteoarthritis. Exp Ther Med. 2020;19(3):1626-32.

27. Ludlow AT, Spangenburg EE, Chin ER, Cheng WH, Roth SM. Telomeres shorten in response to oxidative stress in mouse skeletal muscle fibers. J Gerontol A Biol Sci Med Sci. 2014;69(7):821-30.

28. Zhang J, Rane G, Dai X, Shanmugam MK, Arfuso F, Samy RP, et al. Ageing and the telomere connection: an intimate relationship with inflammation. Ageing Res Rev. 2016;25:55-69.

29. Poonpet T, Saetan N, Tanavalee A, Wilairatana V, Yuktanandana P, Honsawek S. Association between leukocyte telomere length and angiogenic cytokines in knee osteoarthritis. Int J Rheum Dis. 2018;21(1):118-25.

30. Loeser RF. Aging and osteoarthritis. Curr Opin Rheumatol. 2011;23(5):492-6.

31. Wang $T$, Wu X, Al Rudaisat M, Song $Y$, Cheng $H$. Curcumin induces G2/M arrest and triggers autophagy, ROS generation and cell senescence in cervical cancer cells. J Cancer. 2020;11(22):6704-15.

32. Yu S, Cheng Y, Li B, Xue J, Yin Y, Gao J, et al. M1 macrophages accelerate renal glomerular endothelial cell senescence through reactive oxygen species accumulation in streptozotocin-induced diabetic mice. Int Immunopharmacol. 2020;81:106294.

33. Kumar R, Sharma A, Gupta M, Padwad Y, Sharma R. Cell-free culture supernatant of probiotic Lactobacillus fermentum protects against $\mathrm{H}(2) \mathrm{O}(2)$-induced premature senescence by suppressing ROS-AktmTOR axis in murine preadipocytes. Probiot Antimicrob Proteins. 2020;12(2):563-76.

34. Li D, Xie G, Wang W. Reactive oxygen species: the 2-edged sword of osteoarthritis. Am J Med Sci. 2012;344(6):486-90.

35. Henrotin Y, Kurz B, Aigner T. Oxygen and reactive oxygen species in cartilage degradation: friends or foes? Osteoarthr Cartil. 2005;13(8):643-54.

36. Loeser RF, Kelley KL, Armstrong A, Collins JA, Diekman BO, Carlson CS. Deletion of JNK enhances senescence in joint tissues and increases the severity of age-related osteoarthritis in mice. Arthritis Rheumatol (Hoboken, NJ). 2020;72(10):1679-88.

37. Koike M, Nojiri H, Ozawa Y, Watanabe K, Muramatsu Y, Kaneko H, et al. Mechanical overloading causes mitochondrial superoxide and SOD2 imbalance in chondrocytes resulting in cartilage degeneration. Sci Rep. 2015;5:11722.

38. Loeser RF, Collins JA, Diekman BO. Ageing and the pathogenesis of osteoarthritis. Nat Rev Rheumatol. 2016;12(7):412-20.

39. Hui W, Young DA, Rowan AD, Xu X, Cawston TE, Proctor CJ. Oxidative changes and signalling pathways are pivotal in initiating age-related changes in articular cartilage. Ann Rheum Dis. 2016;75(2):449-58. 
40. Bolduc JA, Collins JA, Loeser RF. Reactive oxygen species, aging and articular cartilage homeostasis. Free Radic Biol Med. 2019;132:73-82.

41. Au M, Liu Z, Rong L, Zheng Y, Wen C. Endothelin-1 induces chondrocyte senescence and cartilage damage via endothelin receptor type B in a post-traumatic osteoarthritis mouse model. Osteoarthr Cartil. 2020;28(12):1559-71.

42. Diekman BO, Sessions GA, Collins JA, Knecht AK, Strum SL, Mitin NK, et al. Expression of p16(INK) (4a) is a biomarker of chondrocyte aging but does not cause osteoarthritis. Aging Cell. 2018;17(4):e12771.

43. Baker DJ, Childs BG, Durik M, Wijers ME, Sieben CJ, Zhong J, et al. Naturally occurring p16(Ink4a)-positive cells shorten healthy lifespan. Nature. 2016;530(7589):184-9.

44. Sharpless NE, Sherr CJ. Forging a signature of in vivo senescence. Nat Rev Cancer. 2015;15(7):397-408.

45. Chai B, Zheng ZH, Liao X, Li KY, Liang JS, Huang YX, et al. The protective role of omentin-1 in IL-1 $\beta$-induced chondrocyte senescence. Artific Cells, Nanomed Biotechnol. 2020;48(1):8-14.

46. Acosta JC, Banito A, Wuestefeld T, Georgilis A, Janich P, Morton JP, et al. A complex secretory program orchestrated by the inflammasome controls paracrine senescence. Nat Cell Biol. 2013;15(8):978-90.

47. Lopes-Paciencia S, Saint-Germain E, Rowell MC, Ruiz AF, Kalegari P, Ferbeyre $\mathrm{G}$. The senescence-associated secretory phenotype and its regulation. Cytokine. 2019;117:15-22.

48. Kumari R, Jat P. Mechanisms of cellular senescence: cell cycle arrest and senescence associated secretory phenotype. Front Cell Dev Biol. 2021;9:645593.

49. Greene MA, Loeser RF. Aging-related inflammation in osteoarthritis. Osteoarthr Cartil. 2015;23(11):1966-71.

50. Hamilton JL, Nagao M, Levine BR, Chen D, Olsen BR, Im HJ. Targeting VEGF and its receptors for the treatment of osteoarthritis and associated pain. J Bone Mineral Res. 2016;31(5):911-24.

51. Faust HJ, Zhang H, Han J, Wolf MT, Jeon OH, Sadtler K, et al. IL-17 and immunologically induced senescence regulate response to injury in osteoarthritis. J Clin Invest. 2020;130(10):5493-507.

52. Soto-Gamez A, Demaria M. Therapeutic interventions for aging: the case of cellular senescence. Drug Discov Today. 2017;22(5):786-95.

53. Acosta JC, O'Loghlen A, Banito A, Guijarro MV, Augert A, Raguz S, et al. Chemokine signaling via the CXCR2 receptor reinforces senescence. Cell. 2008;133(6):1006-18.

54. Zhu Y, Tchkonia T, Pirtskhalava T, Gower AC, Ding H, Giorgadze N, et al. The Achilles' heel of senescent cells: from transcriptome to senolytic drugs. Aging Cell. 2015;14(4):644-58.

55. Kirkland JL, Tchkonia T. Cellular senescence: a translational perspective. EBioMedicine. 2017;21:21-8.

56. Kirkland JL, Tchkonia T, Zhu Y, Niedernhofer LJ, Robbins PD. The clinical potential of senolytic drugs. J Am Geriatr Soc. 2017:65(10):2297-301.

57. He S, Sharpless NE. Senescence in health and disease. Cell. 2017;169(6):1000-11.

58. Mas-Bargues C, Borrás C, Viña J. BCl-xL as a modulator of senescence and aging. Int J Mol Sci. 2021;22(4):1527.

59. Camuzard O, Santucci-Darmanin S, Carle GF, Pierrefite-Carle V. Role of autophagy in osteosarcoma. J Bone Oncol. 2019;16:100235.

60. Ren J, Zhang Y. Targeting autophagy in aging and aging-related cardiovascular diseases. Trends Pharmacol Sci. 2018;39(12):1064-76.

61. Zhang Y, Sowers JR, Ren J. Targeting autophagy in obesity: from pathophysiology to management. Nat Rev Endocrinol. 2018;14(6):356-76.

62. Cassidy LD, Narita M. CELL BIOLOGY. GATA get a hold on senescence. Science (New York, NY). 2015;349(6255):1448-9.

63. Kang C, Xu Q, Martin TD, Li MZ, Demaria M, Aron L, et al. The DNA damage response induces inflammation and senescence by inhibiting autophagy of GATA4. Science (New York, NY). 2015;349(6255):aaa5612.

64. Chen X, Gong W, Shao X, Shi T, Zhang L, Dong J, et al. METTL3-mediated $\mathrm{m}(6)$ A modification of ATG7 regulates autophagy-GATA4 axis to promote cellular senescence and osteoarthritis progression. Ann Rheum Dis. 2022;81(1):87-99.

65. Yang ZJ, Chee CE, Huang S, Sinicrope FA. The role of autophagy in cancer: therapeutic implications. Mol Cancer Ther. 2011;10(9):1533-41.

66. Zhang Y, Vasheghani F, Li YH, Blati M, Simeone K, Fahmi H, et al. Cartilage-specific deletion of mTOR upregulates autophagy and protects mice from osteoarthritis. Ann Rheum Dis. 2015;74(7):1432-40.
67. Pal B, Endisha H, Zhang Y, Kapoor M. mTOR: a potential therapeutic target in osteoarthritis? Drugs R\&D. 2015;15(1):27-36.

68. Chen J, Crawford R, Xiao Y. Vertical inhibition of the PI3K/Akt/ mTOR pathway for the treatment of osteoarthritis. J Cell Biochem. 2013;114(2):245-9.

69. Song $B$, Song $H$, Wang W, Wang $H$, Peng $H$, Cui J, et al. Beclin 1 overexpression inhibits chondrocyte apoptosis and downregulates extracellular matrix metabolism in osteoarthritis. Mol Med Rep. 2017:16(4):3958-64.

70. Picard C, Azeddine B, Moldovan F, Martel-Pelletier J, Moreau A. New emerging role of pitx1 transcription factor in osteoarthritis pathogenesis. Clin Orthop Relat Res. 2007:462:59-66.

71. Zhao X, Huang P, Li G, Feng Y, Zhendong L, Zhou C, et al. Overexpression of Pitx 1 attenuates the senescence of chondrocytes from osteoarthritis degeneration cartilage-a self-controlled model for studying the etiology and treatment of osteoarthritis. Bone. 2020;131:115177.

72. Bouderlique T, Vuppalapati KK, Newton PT, Li L, Barenius B, Chagin AS. Targeted deletion of Atg5 in chondrocytes promotes age-related osteoarthritis. Ann Rheum Dis. 2016;75(3):627-31.

73. Caramés B, Hasegawa A, Taniguchi N, Miyaki S, Blanco FJ, Lotz M. Autophagy activation by rapamycin reduces severity of experimental osteoarthritis. Ann Rheum Dis. 2012;71(4):575-81.

74. Dhanabalan KM, Gupta VK, Agarwal R. Rapamycin-PLGA microparticles prevent senescence, sustain cartilage matrix production under stress and exhibit prolonged retention in mouse joints. Biomater Sci. 2020;8(15):4308-21

75. Wallace DC. A mitochondrial bioenergetic etiology of disease. J Clin Invest. 2013;123(4):1405-12.

76. Palikaras K, Lionaki E, Tavernarakis N. Mechanisms of mitophagy in cellular homeostasis, physiology and pathology. Nat Cell Biol. 2018;20(9):1013-22.

77. Shin HJ, Park H, Shin N, Kwon HH, Yin Y, Hwang JA, et al. Pink1-mediated chondrocytic mitophagy contributes to cartilage degeneration in osteoarthritis. J Clin Med. 2019;8(11):1849.

78. Ansari MY, Khan NM, Ahmad I, Haqqi TM. Parkin clearance of dysfunctional mitochondria regulates ROS levels and increases survival of human chondrocytes. Osteoarthr Cartil. 2018;26(8):1087-97.

79. Wang C, Yang Y, Zhang Y, Liu J, Yao Z, Zhang C. Protective effects of metformin against osteoarthritis through upregulation of SIRT3-mediated PINK1/Parkin-dependent mitophagy in primary chondrocytes. Biosci Trends. 2019;12(6):605-12.

80. Farr JN, Fraser DG, Wang H, Jaehn K, Ogrodnik MB, Weivoda MM, et al. Identification of senescent cells in the bone microenvironment. J Bone Mineral Res. 2016;31(11):1920-9.

81. Bhosale AM, Richardson JB. Articular cartilage: structure, injuries and review of management. Br Med Bull. 2008:87:77-95.

82. Xu M, Bradley EW, Weivoda MM, Hwang SM, Pirtskhalava T, Decklever T, et al. Transplanted senescent cells induce an osteoarthritis-like condition in mice. J Gerontol A Biol Sci Med Sci. 2017:72(6):780-5.

83. Jeon $\mathrm{OH}$, Kim C, Laberge RM, Demaria M, Rathod S, Vasserot AP, et al. Local clearance of senescent cells attenuates the development of posttraumatic osteoarthritis and creates a pro-regenerative environment. Nat Med. 2017:23(6):775-81.

84. Zhou HW, Lou SQ, Zhang K. Recovery of function in osteoarthritic chondrocytes induced by p16INK4a-specific siRNA in vitro. Rheumatology (Oxford). 2004;43(5):555-68.

85. Akasaki Y, Reixach N, Matsuzaki T, Alvarez-Garcia O, Olmer M, Iwamoto Y, et al. Transthyretin deposition in articular cartilage: a novel mechanism in the pathogenesis of osteoarthritis. Arthritis Rheumatol (Hoboken, NJ). 2015:67(8):2097-107

86. Wang Y, Zhao X, Lotz M, Terkeltaub R, Liu-Bryan R. Mitochondrial biogenesis is impaired in osteoarthritis chondrocytes but reversible via peroxisome proliferator-activated receptor $\gamma$ coactivator 1a. Arthritis Rheumatol (Hoboken, NJ). 2015:67(8):2141-53.

87. Xu M, Feng M, Peng H, Qian Z, Zhao L, Wu S. Epigenetic regulation of chondrocyte hypertrophy and apoptosis through Sirt1/P53/P21 pathway in surgery-induced osteoarthritis. Biochem Biophys Res Commun. 2020;528(1):179-85.

88. Jeon OH, Wilson DR, Clement CC, Rathod S, Cherry C, Powell B, et al. Senescence cell-associated extracellular vesicles serve as osteoarthritis disease and therapeutic markers. JCl insight. 2019:4(7):e125019. 
89. Hall BM, Balan V, Gleiberman AS, Strom E, Krasnov P, Virtuoso LP, et al. p16(Ink4a) and senescence-associated $\beta$-galactosidase can be induced in macrophages as part of a reversible response to physiological stimuli. Aging. 2017;9(8):1867-84.

90. Feng $\mathrm{M}$, Peng $\mathrm{H}$, Yao $\mathrm{R}$, Zhang $Z$, Mao $\mathrm{G}$, Yu H, et al. Inhibition of cellular communication network factor 1 (CCN1)-driven senescence slows down cartilage inflammaging and osteoarthritis. Bone. 2020;139:115522.

91. Fang H, Huang L, Welch I, Norley C, Holdsworth DW, Beier F, et al. Early changes of articular cartilage and subchondral bone in the DMM mouse model of osteoarthritis. Sci Rep. 2018;8(1):2855.

92. Pragnère $\mathrm{S}$, Boulocher $\mathrm{C}$, Pollet $\mathrm{O}$, Bosser $\mathrm{C}$, Levillain $\mathrm{A}$, Cruel M, et al. Mechanical alterations of the bone-cartilage unit in a rabbit model of early osteoarthrosis. J Mech Behav Biomed Mater. 2018;83:1-8.

93. Zhao DL, Li HT, Liu SH. TIMP3/TGF- $\beta 1$ axis regulates mechanical loading-induced chondrocyte degeneration and angiogenesis. Mol Med Rep. 2020;22(4):2637-44.

94. Sanchez C, Mazzucchelli G, Lambert C, Comblain F, DePauw E, Henrotin Y. Comparison of secretome from osteoblasts derived from sclerotic versus non-sclerotic subchondral bone in OA: A pilot study. PLoS One. 2018;13(3):e0194591.

95. Cabahug-Zuckerman P, Frikha-Benayed D, Majeska RJ, Tuthill A, Yakar $\mathrm{S}$, Judex $\mathrm{S}$, et al. Osteocyte apoptosis caused by hindlimb unloading is required to trigger osteocyte RANKL production and subsequent resorption of cortical and trabecular bone in mice femurs. J Bone Mineral Res. 2016;31(7):1356-65.

96. Plotkin LI, Gortazar AR, Davis HM, Condon KW, Gabilondo H, Maycas M, et al. Inhibition of osteocyte apoptosis prevents the increase in osteocytic receptor activator of nuclear factor $\mathrm{KB}$ ligand (RANKL) but does not stop bone resorption or the loss of bone induced by unloading. J Biol Chem. 2015;290(31):18934-42.

97. He Z, Li H, Han X, Zhou F, Du J, Yang Y, et al. Irisin inhibits osteocyte apoptosis by activating the Erk signaling pathway in vitro and attenuates ALCT-induced osteoarthritis in mice. Bone. 2020;141:115573. https://doi.org/10.1016/.bone.2020.115573.

98. Lu J, Zhang H, Cai D, Zeng C, Lai P, Shao Y, et al. Positive-feedback regulation of subchondral $\mathrm{H}$-Type vessel formation by chondrocyte promotes osteoarthritis development in mice. J Bone Mineral Res. 2018;33(5):909-20.

99. Sanchez C, Deberg MA, Bellahcène A, Castronovo V, Msika P, Delcour JP, et al. Phenotypic characterization of osteoblasts from the sclerotic zones of osteoarthritic subchondral bone. Arthritis Rheum. 2008;58(2):442-55.

100. Kennedy OD, Laudier DM, Majeska RJ, Sun HB, Schaffler MB. Osteocyte apoptosis is required for production of osteoclastogenic signals following bone fatigue in vivo. Bone. 2014;64:132-7.

101. Li J, Xue J, Jing Y, Wang M, Shu R, Xu H, et al. SOST deficiency aggravates osteoarthritis in mice by promoting sclerosis of subchondral bone. Biomed Res Int. 2019;2019:7623562.

102. Jung YK, Han MS, Park HR, Lee EJ, Jang JA, Kim GW, et al. Calcium-phosphate complex increased during subchondral bone remodeling affects earlystage osteoarthritis. Sci Rep. 2018;8(1):487.

103. Chang TK, Wang YH, Kuo SJ, Wang SW, Tsai CH, Fong YC, et al. Apelin enhances IL-1 $\beta$ expression in human synovial fibroblasts by inhibiting miR-144-3p through the PI3K and ERK pathways. Aging. 2020;12(10):9224-39.

104. Chen QN, Fan Z, Lyu AK, Wu J, Guo A, Yang YF, et al. Effect of sarcolipinmediated cell transdifferentiation in sarcopenia-associated skeletal muscle fibrosis. Exp Cell Res. 2020;389(1):111890.

105. Qin W, Dallas SL. Exosomes and extracellular RNA in muscle and bone aging and crosstalk. Curr Osteoporos Rep. 2019;17(6):548-59.

106. Dai J, Dong R, Han X, Li J, Gong X, Bai Y, et al. Osteoclast-derived exosomal let-7a-5p targets Smad2 to promote the hypertrophic differentiation of chondrocytes. Am J Physiol Cell Physiol. 2020. https://doi.org/10. 1152/ajpcell.00039.2020.

107. Hu W, Chen Y, Dou C, Dong S. Microenvironment in subchondral bone: predominant regulator for the treatment of osteoarthritis. Ann Rheum Dis. 2020;80(4):413-22.
108. Goldring SR. Alterations in periarticular bone and cross talk between subchondral bone and articular cartilage in osteoarthritis. Therapeut Adv Musculoskel Dis. 2012;4(4):249-58.

109. Zhao X, Xie L, Wang Z, Wang J, Xu H, Han X, et al. ZBP1 (DAI/DLM-1) promotes osteogenic differentiation while inhibiting adipogenic differentiation in mesenchymal stem cells through a positive feedback loop of Wnt/ $\beta$-catenin signaling. Bone Res. 2020;8:12.

110. Stegen S, Stockmans I, Moermans K, Thienpont B, Maxwell PH, Carmeliet $\mathrm{P}$, et al. Osteocytic oxygen sensing controls bone mass through epigenetic regulation of sclerostin. Nat Commun. 2018;9(1):2557.

111. Yang H, Chen C, Chen H, Duan X, Li J, Zhou Y, et al. Navitoclax (ABT263) reduces inflammation and promotes chondrogenic phenotype by clearing senescent osteoarthritic chondrocytes in osteoarthritis. Aging. 2020;12(13):12750-70.

112. Del Rey MJ, Valín Á, Usategui A, Ergueta S, Martín E, Municio C, et al. Senescent synovial fibroblasts accumulate prematurely in rheumatoid arthritis tissues and display an enhanced inflammatory phenotype. Immun Ageing. 2019;16:29.

113. Felson DT. Osteoarthritis as a disease of mechanics. Osteoarthr Cartil. 2013;21(1):10-5.

114. Wang W, Li J, Li F, Peng J, Xu M, Shangguan Y, et al. Scutellarin suppresses cartilage destruction in osteoarthritis mouse model by inhibiting the NF-KB and PI3K/AKT signaling pathways. Int Immunopharmacol. 2019;77:105928.

115. Singh $T$, Newman AB. Inflammatory markers in population studies of aging. Ageing Res Rev. 2011;10(3):319-29.

116. Di Nicola V. Degenerative osteoarthritis a reversible chronic disease. Regenerat Ther. 2020;15:149-60.

117. Xu J, She G, Gui T, Hou H, Li J, Chen Y, et al. Knee muscle atrophy is a risk factor for development of knee osteoarthritis in a rat model. J Orthop Transl. 2020:22:67-72.

118. Yamakawa H, Kusumoto D, Hashimoto H, Yuasa S. Stem cell aging in skeletal muscle regeneration and disease. Int J Mol Sci. 2020;21(5):1830.

119. da Silva PFL, Ogrodnik M, Kucheryavenko O, Glibert J, Miwa S, Cameron $\mathrm{K}$, et al. The bystander effect contributes to the accumulation of senescent cells in vivo. Aging Cell. 2019;18(1):e12848.

120. Hickson LJ, Langhi Prata LGP, Bobart SA, Evans TK, Giorgadze N, Hashmi SK, et al. Senolytics decrease senescent cells in humans: preliminary report from a clinical trial of Dasatinib plus Quercetin in individuals with diabetic kidney disease. EBioMedicine. 2019;47:446-56.

121. Xu M, Pirtskhalava T, Farr JN, Weigand BM, Palmer AK, Weivoda MM, et al. Senolytics improve physical function and increase lifespan in old age. Nat Med. 2018;24(8):1246-56.

122. Farr JN, Xu M, Weivoda MM, Monroe DG, Fraser DG, Onken JL, et al. Targeting cellular senescence prevents age-related bone loss in mice. Nat Med. 2017:23(9):1072-9.

123. He Y, Li W, Lv D, Zhang X, Zhang X, Ortiz YT, et al. Inhibition of USP7 activity selectively eliminates senescent cells in part via restoration of p53 activity. Aging Cell. 2020;19(3):e13117.

124. Shen $\mathrm{H}$, Maki CG. Pharmacologic activation of $\mathrm{p} 53$ by small-molecule MDM2 antagonists. Curr Pharm Des. 2011;17(6):560-8.

125. Zhang L, Luo J, Wen H, Zhang T, Zuo X, Li X. MDM2 promotes rheumatoid arthritis via activation of MAPK and NF-KB. Int Immunopharmacol. 2016;30:69-73.

126. Schieker M, Conaghan PG, Mindeholm L, Praestgaard J, Solomon DH, Scotti $C$, et al. Effects of interleukin-1 $\beta$ inhibition on incident hip and knee replacement : exploratory analyses from a randomized, doubleblind, placebo-controlled trial. Ann Intern Med. 2020;173(7):509-15.

127. Wang M, Sampson ER, Jin H, Li J, Ke QH, Im HJ, et al. MMP13 is a critical target gene during the progression of osteoarthritis. Arthritis Res Ther. 2013;15(1):R5

128. Cai $X$, Yuan S, Zeng Y, Wang C, Yu N, Ding C. New trends in pharmacological treatments for osteoarthritis. Front Pharmacol. 2021;12:645842.

129. Zhang XX, He SH, Liang X, Li W, Li TF, Li DF. Aging, cell senescence, the pathogenesis and targeted therapies of osteoarthritis. Front Pharmacol. 2021:12:728100.

130. Zhang L, Pitcher LE, Prahalad V, Niedernhofer LJ, Robbins PD. Recent advances in the discovery of senolytics. Mech Ageing Dev. 2021;200:111587. 
131. Kang C. Senolytics and senostatics: a two-pronged approach to target cellular senescence for delaying aging and age-related diseases. Mol Cells. 2019;42(12):821-7.

132. Staines KA, Poulet B, Wentworth DN, Pitsillides AA. The STR/ort mouse model of spontaneous osteoarthritis - an update. Osteoarthr Cartil. 2017;25(6):802-8.

133. Burd CE, Sorrentino JA, Clark KS, Darr DB, Krishnamurthy J, Deal $A M$, et al. Monitoring tumorigenesis and senescence in vivo with a p16(INK4a)-luciferase model. Cell. 2013;152(1-2):340-51.

134. Malaise $\mathrm{O}$, Tachikart Y, Constantinides M, Mumme M, Ferreira-Lopez $R$, Noack $S$, et al. Mesenchymal stem cell senescence alleviates their intrinsic and seno-suppressive paracrine properties contributing to osteoarthritis development. Aging. 2019;11(20):9128-46.

135. Kamekura S, Hoshi K, Shimoaka T, Chung U, Chikuda H, Yamada T, et al. Osteoarthritis development in novel experimental mouse models induced by knee joint instability. Osteoarthr Cartil. 2005;13(7):632-41.

136. Nagira K, Ikuta Y, Shinohara M, Sanada Y, Omoto T, Kanaya H, et al. Histological scoring system for subchondral bone changes in murine models of joint aging and osteoarthritis. Sci Rep. 2020;10(1):10077.

137. Culley KL, Singh P, Lessard S, Wang M, Rourke B, Goldring MB, et al. Mouse models of osteoarthritis: surgical model of post-traumatic osteoarthritis induced by destabilization of the medial meniscus. Methods Mol Biol (Clifton, NJ). 2021;2221:223-60.

138. Azman KF, Zakaria R. D-Galactose-induced accelerated aging model: an overview. Biogerontology. 2019;20(6):763-82.

139. Gao L, Wang M, Liao L, Gou N, Xu P, Ren Z, et al. A Slc25a46 mouse model simulating age-associated motor deficit, redox imbalance, and mitochondria dysfunction. J Gerontol A Biol Sci Med Sci. 2021;76(3):440-7.

140. Glasson SS, Askew R, Sheppard B, Carito B, Blanchet T, Ma HL, et al. Deletion of active ADAMTS5 prevents cartilage degradation in a murine model of osteoarthritis. Nature. 2005;434(7033):644-8.

141. Lanctôt C, Moreau A, Chamberland M, Tremblay ML, Drouin J. Hindlimb patterning and mandible development require the Ptx 1 gene. Development. 1999;126(9):1805-10.

142. Nagy E, Vajda E, Vari C, Sipka S, Fárr AM, Horváth E. Meloxicam ameliorates the cartilage and subchondral bone deterioration in monoiodoacetate-induced rat osteoarthritis. PeerJ. 2017;5:e3185.

143. Guzman RE, Evans MG, Bove S, Morenko B, Kilgore K. Mono-iodoacetate-induced histologic changes in subchondral bone and articular cartilage of rat femorotibial joints: an animal model of osteoarthritis. Toxicol Pathol. 2003;31(6):619-24.

144. van Vliet T, Varela-Eirin M, Wang B, Borghesan M, Brandenburg SM, Franzin $\mathrm{R}$, et al. Physiological hypoxia restrains the senescence-associated secretory phenotype via AMPK-mediated mTOR suppression. Mol Cell. 2021;81(9):2041-2052.e6.

145. Jeong J, Bae K, Kim SG, Kwak D, Moon YJ, Choi CH, et al. Anti-osteoarthritic effects of ChondroT in a rat model of collagenase-induced osteoarthritis. BMC Complement Altern Med. 2018;18(1):131.

146. Lin M, Lin Y, Li X, Liang W, Wang S, Liu J, et al. Warm sparse-dense wave inhibits cartilage degradation in papain-induced osteoarthritis through the mitogen-activated protein kinase signaling pathway. Exp Ther Med. 2017;14(4):3674-80.

147. Correia-Melo C, Marques FD, Anderson R, Hewitt G, Hewitt R, Cole J, et al. Mitochondria are required for pro-ageing features of the senescent phenotype. EMBO J. 2016;35(7):724-42.

148. Wiley CD, Schaum N, Alimirah F, Lopez-Dominguez JA, Orjalo AV, Scott $\mathrm{G}$, et al. Small-molecule MDM2 antagonists attenuate the senescenceassociated secretory phenotype. Sci Rep. 2018;8(1):2410.

149. Peilin W, Songsong T, Chengyu Z, Zhi C, Chunhui M, Yinxian Y, et al. Directed elimination of senescent cells attenuates development of osteoarthritis by inhibition of c-IAP and XIAP. Biochim Biophys Acta Mol Basis Dis. 2019;1865(10):2618-32.

\section{Publisher's Note}

Springer Nature remains neutral with regard to jurisdictional claims in published maps and institutional affiliations.

Ready to submit your research? Choose BMC and benefit from:

- fast, convenient online submission

- thorough peer review by experienced researchers in your field

- rapid publication on acceptance

- support for research data, including large and complex data types

- gold Open Access which fosters wider collaboration and increased citations

- maximum visibility for your research: over 100M website views per year

At BMC, research is always in progress.

Learn more biomedcentral.com/submissions 